\title{
EL PRINCIPIO DE COHERENCIA EN EL DERECHO INTERNACIONAL PRIVADO EUROPEO*
}

\author{
Sixto A. SÁNCHEZ LORENZO **
}

SUMARIO: 1 . DEFINICIÓN DEL PRINCIPIO DE COHERENCIA.-2. COHERENCIA VERTICAL, HORIZONTAL Y TRANSVERSAL.-3. LAS DIFICULTADES DE UNA INTERPRETACIÓN SISTEMÁTICA SIN SISTEMA: EL MITO DE LAS NOCIONES AUTÓNOMAS.-4. COHERENCIA NO ES PARALELISMO.-4.1. Competencia judicial internacional y Derecho aplicable.-4.2. Derecho conflictual y Derecho material.-5. CONCLUSIÓN: EL JUEGO DE LOS VALORES DEBILITA LA UNIDAD DE LOS CONCEPTOS.

\section{DEFINICIÓN DEL PRINCIPIO DE COHERENCIA}

1. La formulación de sendos considerandos en los Reglamentos «Roma I» $\mathrm{y}$ «Roma II» se reputa como la plasmación legislativa de un principio que ya cabía inferir de la jurisprudencia y de la doctrina en materia de Derecho internacional privado europeo: el principio de coherencia ${ }^{1}$. El principio atiende

* Este trabajo desarrolla una parte de los argumentos expuestos por el autor con motivo de su ponencia en el III Seminario AEPDIRI sobre temas de actualidad de Derecho internacional privado, celebrada el 25 de enero de 2018 en Valencia, y que ya se encuentran apuntados de forma más sintética en la publicación de dicho seminario bajo el título «Cincuenta años de Derecho internacional privado de la Unión Europea: el lado oscuro».

** Catedrático de Derecho internacional privado de la Universidad de Granada.

1 «El ámbito de aplicación material y las disposiciones del presente Reglamento deben garantizar la coherencia con el Reglamento (CE) núm. 44/2001 del Consejo, de 22 de diciembre de 2000, relativo a la competencia judicial, el reconocimiento y la ejecución de resoluciones judiciales en materia civil y mercantil (Bruselas I), y el Reglamento (CE) núm. 864/2007, del Parlamento Europeo y del Consejo, de 11 de julio, sobre la ley aplicable a las obligaciones extracontractuales (Roma II)» [considerando 7 del Reglamento (CE) núm. 593/2008, del Parlamento Europeo y del Consejo, de 17 de junio, sobre la ley aplicable a las obligaciones contractuales (Roma I), DO L núm. 177, de 4 de julio de 2008]. «El ámbito de aplicación material y las disposiciones del presente Reglamento deben garantizar la coherencia con el Reglamento (CE) núm. 44/2001 del Consejo, de 22 de diciembre de 2000, relativo a la competencia judicial, el reconocimiento y la ejecución de resoluciones judiciales en materia civil y mercantil (5) (Bruselas I), y con los instrumentos que tratan sobre la ley aplicable a las obligaciones contractuales» [considerando 7 del Reglamento (CE) núm. 864/2007, del Parlamento Europeo y del Consejo, de 11 de julio, relativo a la ley aplicable a las obligaciones extracontractuales («Roma II»), DO L núm. 199, de 31 de julio de 2007]. 
esencialmente a la necesidad de una coherencia entre las reglas y conceptos jurídicos que se contienen en las distintas normas de Derecho internacional privado europeo, tanto en su formulación como en su interpretación. En cierto sentido, el principio de coherencia apunta a la idea de «sistema jurídico». Resultaría redundante hablar de "coherencia sistemática», en la medida en que la propia noción de «sistema» y, en concreto, de «sistema jurídico» conlleva la idea de relación y orden entre todas sus reglas.

2. Es posible que la plasmación de este principio en los considerandos de los reglamentos europeos citados haya sido más perjudicial que beneficiosa. Los considerandos mencionan el ámbito de aplicación y las disposiciones de ambos reglamentos como objeto de la coherencia que es preciso garantizar entre ambos reglamentos entre sí y en sus relaciones con el Reglamento «Bruselas I» ${ }^{2}$. La propia evolución de los textos legales y de la jurisprudencia del TJUE sobre las numerosas cuestiones prejudiciales planteadas en torno a la cooperación judicial internacional en materia civil invitaba a entender el principio como "paralelismo», como coincidencia en la delimitación del ámbito de aplicación, en la calificación de las materias (contractual y no contractual), en el sentido de los conceptos («consumidor», «lugar donde el trabajador realiza habitualmente su trabajo») y en el alcance de las normas jurídicas (consumidores o trabajadores que se benefician al mismo tiempo de los foros de protección y de las normas de Derecho aplicable tuitivas).

3. El objeto de este estudio es demostrar el error de este planteamiento y su esencia involutiva. La univocidad de los conceptos y el paralelismo de las reglas dotan al sistema de Derecho internacional privado europeo de sencillez en la interpretación y mayor seguridad jurídica subjetiva o previsibilidad. Permite construir, además, un modelo apolíneo, rígido y sólido, en que cualquier término jurídico significa exactamente lo mismo con independencia del cuerpo normativo en que aparezca. Pero semejantes virtudes formales traicionan de raíz el principio más elemental de la justicia material, conforme al cual las reglas y su interpretación deben servir al objetivo de política legislativa trazado, a los valores, en suma, a los que sirven las normas como pistas orientativas. El contexto de las normas y de los conceptos se erige, entonces, en un elemento determinante de un modelo dionisiaco, no paradigmático, o posmoderno si se quiere, en el que cada concepto y cada regla se reconstruye de manera singular en cada caso concreto en atención a su ubicación dentro del sistema jurídico y a la articulación de sus objetivos. En suma, se trata de aceptar la realidad del sistema jurídico como una unidad compleja, en el sentido expuesto por Niklas Luhmann ${ }^{3}$. De este modo, es el matiz, la di-

2 Reglamento (CE) núm. 44/2001, del Consejo, de 22 de diciembre de 2000, relativo a la competencia judicial, el reconocimiento y la ejecución de resoluciones judiciales en materia civil y mercantil (Bruselas I, DO L núm. 12, de 16 de enero de 2001) sustituido por el Reglamento (CE) núm. 1215/2012, del Parlamento Europeo y del Consejo, de 12 de diciembre, relativo a la competencia judicial, el reconocimiento y la ejecución de resoluciones judiciales en materia civil y mercantil (Bruselas I bis, DO L núm. 351, de 20 de diciembre de 2012).

3 Véase Luhmann, N., Sistema jurídico y dogmática jurídica, Madrid, Centro de Estudios Constitucionales, 1983, p. 37. 
ferencia o la reconstrucción dialéctica del concepto a la luz del caso concreto los que proporcionan calidad al proceso normativo e interpretativo y afinan $a$ posteriori la justicia material hic et nunc. En contrapartida, el principio de coherencia entendido como paralelismo habilita un desiderátum, un haz de herramientas simplificado y apriorístico que elimina la diferencia dialécticamente justificada. Por ello, el correcto entendimiento del juego del principio de coherencia en el Derecho internacional privado europeo requiere asumir no solo su falibilidad, sino también su relatividad consustancial.

4. Antes de demostrar de forma empírica los malos resultados a que conduce comprender el principio de coherencia en términos de "paralelismo», necesitamos perfilar con más precisión cuáles son el objeto y las dimensiones del principio de coherencia. La propia referencia a un "principio», se entiende que «jurídico», obliga a reflexionar sobre el sentido del término. El principio de coherencia no es un principio normativo propiamente dicho, ni tampoco ético-jurídico en el sentido «larenziano», sino un principio esencialmente interpretativo. En cierto sentido, el principio apunta a la necesidad de una interpretación sistemática de las distintas normas de Derecho internacional privado, que deberán ser comprendidas las unas por las otras, de forma que se garantice la unidad y la máxima eficacia de todo el sistema jurídico. Desde este punto de vista, el principio de coherencia apunta esencialmente al intérprete y, por tanto, se decanta en la jurisprudencia. De ahí que la cuestión prejudicial sea la piedra angular del principio de coherencia ${ }^{4}$.

5. Pero el principio de coherencia se manifiesta asimismo como principio informador en el plano legislativo previo. El Derecho privado europeo nos proporciona un ejemplo singular del alcance de este principio de coherencia en clave legislativa: los llamados principios Acquis o Acquis Principles en materia de Derecho contractual europeo. Los trabajos que alumbraron estos principios no pretendían otra cosa que proporcionar al legislador europeo una guía para la coherencia que resolviera los dislates a que habían conducido las sucesivas, variopintas y múltiples directivas europeas en materia de contratos y, singularmente, en materia de consumo, que contenían conceptos y reglas dispares según el tipo de contrato en cada caso, ya se tratara de determinar el juego de derechos básicos como el desistimiento del consumidor, las obligaciones de información del proveedor o la forma del contrato. Estos desajustes, muchas veces injustificados, aconsejaban partir de unos principios básicos que fueran tenidos en cuenta a la hora de refundir, modificar o adoptar nuevas directivas en la materia. En el ámbito del Derecho internacional privado, el principio de coherencia como informador del proceso legislativo cuenta asimismo con ejemplos muy claros, como la incidencia de la evolución del Reglamento «Bruselas I» respecto del Convenio de Bruselas, que tuvo su inmediato trasunto en la evolución del Reglamento «Roma I» respecto del Convenio de Roma de 19 de junio de 1980 sobre la ley aplicable a las obligaciones contractuales, en particular en lo que se refiere a las normas de protección de consumidores y trabajadores.

\footnotetext{
4 Véase infra nota 12.
} 
6. El principio, en consecuencia, requiere una atención legislativa y jurisprudencial para configurar e interpretar las normas y conceptos del Derecho internacional privado de forma sistemática, esto es, coherente. La coherencia se refiere a las reglas jurídicas y a su interpretación, en general, y más específicamente a los conceptos contenidos en dichas normas y a los valores subyacentes. El Derecho internacional privado utiliza conceptos o ideas-fuerza, esos excelentes servidores a que se refiere Denis Lloyd ${ }^{5}$ : "consumidor», "víctima», "daño», "contrato», "residencia habitual», "domicilio», "lugar de ejecución», "parte débil», etc. Una aproximación formalista y simplista del principio de coherencia apuntaría a una aproximación gramatical típicamente literal y a la necesidad de un concepto único y apolíneo de «consumidor» o «domicilio. cualquiera que sea la norma jurídica del Derecho privado europeo en que el término se encuentre. La aproximación dionisiaca requiere un esfuerzo mayor y genera más inseguridad, pues obliga a una interpretación mediatizada por el contexto, en el sentido más actual de una filosofía analítica del lenguaje: "domicilio» de la sociedad puede significar algo muy distinto si el término se encuentra en un reglamento sobre ley aplicable, sobre procedimientos de insolvencia o sobre competencia judicial internacional, o incluso si se trata de interpretar un foro de competencia judicial internacional exclusivo o general. Pero el contexto al que nos referimos no solo es circunstancial, sino axiológico. La coherencia adquiere su verdadera dimensión, y entonces se relativiza, si más allá de los conceptos como servidores, evitamos que se conviertan en muy malos patronos, como advertía igualmente Denis Lloyd. Y esta perversión de los conceptos unívocos se produce cada vez que interpretamos paralelamente conceptos, nociones o reglas jurídicas que se orientan a objetivos o valores de política legislativa diferentes. Si adoptamos vocablos, conceptos y valores como parámetros de acción del principio, la comparación que exige el principio de coherencia no solo es formal o gramatical, sino sustancial, de forma que el paralelismo o la unidad de interpretación solo es posible si se comparten conceptos, nociones y valores, mientras que la diferencia se habilita al justificar dialécticamente una diferencia de objetivos de política legislativa que aconseja e impone una interpretación diferente. Coherencia, pues, puede ser tanto la unidad como la diversidad en la interpretación de un concepto, si adjetivamos el principio no solo formal o gramaticalmente, sino sustancial y axiológicamente. La opción que defendemos es, ciertamente, más incómoda e imprevisible, a posteriori, dialéctica y exigente de un plus de motivación. En contrapartida, es más justa.

7. Puede parecer obvio a un lector neutral que, a la luz de la metodología del Derecho en el siglo XXI, un entendimiento formal del principio de coherencia, ajeno a las oscilaciones axiológicas en los distintos sectores del ordenamiento, resulta absolutamente inapropiado. Sin embargo, la metodología del Derecho europeo presenta singularidades que justifican una querencia particular por una lógica de la integración o de la armonización que,

5 Lloyd, D., La idea de Derecho (¿perversidad represora o necesidad social?), Madrid, Civitas, 1985, p. 320 . 
de manera natural, tiende a procurar la unidad o armonía apolínea de los conceptos, nociones y normas. Esta lógica de la integración o del objetivo de la armonización, como un valor en sí mismo, con excesiva frecuencia anula o mitiga los objetivos o valores de Derecho privado que subyacen en las normas de Derecho internacional privado. Dicho de modo simple, la metodología del Derecho europeo es capaz de sacrificar la justicia por el valor supremo de la armonización. Es una constante que obliga al intérprete y, sobre todo, al analista del Derecho internacional privado europeo, a tratar de corregir, con idéntica dificultad con la que se corrige la querencia hacia las tablas del animal en el arte de Cúchares.

8. Delimitado el juego del principio en sus diversas acepciones y opciones, conviene delimitar, en razón de las fuentes normativas, las manifestaciones del principio de coherencia (2). A renglón seguido, analizaremos el postulado del principio de coherencia, esto es, la existencia y posibilidad de un "sistema de Derecho internacional privado europeo» (3). Finalmente, trataremos de poner de relieve la relatividad del principio de coherencia y los riesgos de su entendimiento en términos de "paralelismo», que es la hipótesis que hemos formulado al inicio de este trabajo (4). A modo de conclusión trataremos de sintetizar la confirmación de la hipótesis formulada (5).

\section{COHERENCIA VERTICAL, HORIZONTAL Y TRANSVERSAL}

9. En razón de las fuentes normativas, cabe referirse a una coherencia vertical, horizontal y transversal, que responden a los distintos supuestos de pluralidad o complejidad de las fuentes normativas del Derecho internacional privado europeo. La pluralidad de fuentes en el Derecho internacional privado europeo se predica, pues, tanto de textos sucesivos sobre la misma materia (vertical) como entre textos relativos a materias o cuestiones diversas (horizontal) ${ }^{6}$. Mientras que «Bruselas I» $\mathrm{y}$ «Bruselas I bis» suscitan problemas de coherencia «vertical», «Bruselas I bis» $\mathrm{y}$ «Roma I» las plantean en la dimensión «horizontal» ${ }^{7}$.

10. El principio de continuidad de la interpretación y de los precedentes jurisprudenciales del TJUE, por ejemplo, desde el Convenio de Bruselas hasta

\footnotetext{
${ }^{6}$ Siguiendo la terminología propuesta por CRAWford, E. B. y CARRUTHERS, J. M., «Connection and Coherence between and among European Instruments in the Private International Law of Obligations", ICLQ, vol. 63, 2004, p. 2.

7 Ciertamente la codificación conjunta y no parcial suele estar en la agenda, si bien las distintas bases jurídicas por razón de la materia constituyen un obstáculo importante [véase sobre el particular DuTTA, H., «Gemeinsame oder getrennte Kodifikation con IPR und IZVR auf europäischer Ebene (Die bisherige und geplanten Verordnungen in Familien und Erbrecht als Vorbilder für andere Rechsgebiete?)», Kohärenz im internationalen Privat -und Verfahrensrecht der Europäischen Union (Jan Von Hein und G. Rühl Hrsg.), Tubinga, Mohr Siebeck, 2016, pp. 27-43]. Una propuesta sobre la base de la Ley Federal suiza de Derecho internacional privado se encuentra en KADNER GrAZIANO, T., «Gemeinsame oder getrennte Kodifikation von IPR und IZVR (Das Schweizerische IPR-Gesetz als Modell für eine europäische Gesamtkodifikation - Lehren für die EU)», Kohärenz, im internationalen Privat -und Verfahrensrecht der Europäischen Union (Jan Von Hein und G. Rühl Hrsg.), Tubinga, Mohr Siebeck, 2016, pp. 27-43.
} 
el Reglamento «Bruselas I bis», es una manifestación del juego de la coherencia vertical, y facilita una interpretación sistemática o coherente entre textos europeos de Derecho internacional privado sucesivos sobre la misma materia.

11. Pero los problemas de coherencia vertical u horizontal no se predican exclusivamente de textos europeos. La coherencia exige asimismo resolver de forma cabal la sucesión de textos sobre la misma materia de origen diverso y, en particular, las complejas interrelaciones entre los textos europeos y los convenios adoptados en el marco de la Conferencia de La Haya de Derecho internacional privado. Estas relaciones, que podríamos englobar en el concepto de «coherencia transversal» o "externa» (frente a la coherencia de fuentes internas o propiamente europeas), tienden a articularse de forma singular, como ocurre en el ámbito de la responsabilidad parental entre el Reglamento «Bruselas II ${ }^{8}$ y el Convenio de La Haya de $1996^{9}$, o entre el Reglamento "Bruselas III» ${ }^{10}$ y el Protocolo de La Haya de 23 de noviembre de 2007 sobre la ley aplicable a las obligaciones alimenticias. Sin embargo, esta articulación no siempre puede resolver los problemas que plantea el cruce de relaciones verticales u horizontales. En la coherencia transversal, el primer reto consiste en dotar de coherencia a los respectivos ámbitos de aplicación, singularmente al espacial ${ }^{11}$. Pero una vez delimitados los ámbitos de aplicación espacial, la existencia de una compatibilidad o diálogo entre las normas

\footnotetext{
${ }^{8}$ Reglamento (CE) núm. 2201/2003, del Consejo, de 27 de noviembre, relativo a la competencia, el reconocimiento y la ejecución de resoluciones judiciales en materia matrimonial y de responsabilidad parental, DO L núm. 338, de 23 de diciembre de 2003.

9 Convenio relativo a la competencia, la ley aplicable, el reconocimiento, la ejecución y la cooperación en materia de responsabilidad parental y de medidas de protección de los niños, hecho en La Haya el 19 de octubre de 1996.

10 Reglamento (CE) núm. 4/2009, del Consejo, de 18 de diciembre de 2008, relativo a la competencia, la ley aplicable, el reconocimiento y la ejecución de resoluciones y la cooperación en materia de obligaciones de alimentos, DO L núm. 7, de 10 de enero de 2009.

${ }^{11}$ La materia de alimentos constituye un excelente ejemplo al respecto [véase ScHULz, A., «Die EU und die Haager Konferez für Internationales Privatrecht», Kohärenz im internationalen Privat -und Verfahrensrecht der Europäischen Union (Jan Von Hein und G. Rühl Hrsg.), Tubinga, Mohr Siebeck, 2016, pp. 110-144, esp. pp. 134-136]. El Protocolo de La Haya de 2007 es un convenio sucesivo respecto de los Convenios de 1958 y 1973. En efecto, el Protocolo de 2007 viene a sustituir al Convenio de La Haya de 2 de octubre de 1973 sobre la ley aplicable a las obligaciones alimenticias, que a su vez sustituía al Convenio de La Haya de 24 de octubre de 1956 sobre la misma materia. En puridad, el Protocolo solo sustituye a los Convenios de La Haya en las relaciones entre los Estados parte (art. 18), lo que excluye las relaciones entre España y países como Liechtenstein, Albania, Japón, Suiza y Turquía. En el caso de Liechtenstein, resultaría aplicable el Convenio de La Haya de 1956 en materia de obligaciones alimenticias respecto de menores de veintiún años solteros que residan en Liechtenstein [GARAU SoBRINO, F., defiende que la aplicación de los Convenios de La Haya se producirá cuando la ley designada por tales convenios sea la de un Estado parte (Liechtenstein, Japón, Suiza o Turquía): véase «Las fuentes españolas en materia de obligaciones alimenticias: ¿Hacia un Derecho internacional privado extravagante?», Cuadernos de Derecho Transnacional, vol. 3, 2011, núm. 2, p. 137]. Tanto el Protocolo como el Convenio de La Haya de 1973 parten de la aplicación universal de sus normas, sin contener otros criterios de delimitación o compatibilidad especial. En puridad, pues, España mantiene un compromiso internacional con dichos Estados que le obliga a aplicar las reglas del Convenio de La Haya de 1973, al menos cuando exista una vinculación con nacionales o personas domiciliadas en dichos Estados. En la práctica, es muy posible que los tribunales españoles apliquen en todas las hipótesis las reglas de Derecho aplicable del Protocolo, singularmente diferentes a las del Convenio de La Haya de 1973, sin que sea de esperar ninguna reclamación internacional de los Estados respecto de los que aún estamos obligados a aplicar el Convenio de La Haya de 1973.
} 
de Derecho internacional privado de origen europeo y convencional imponen lógicas limitaciones al principio de coherencia.

12. La primera de ellas es el debilitamiento de la propia competencia interpretativa del TJUE y, como consecuencia, la imposibilidad de inducir o extrapolar interpretaciones o nociones autónomas inducidas para el Derecho internacional privado europeo. Los convenios de la Conferencia de La Haya de Derecho internacional privado están sujetos, como textos internacionales, a las reglas de interpretación de tratados propias del Derecho internacional, y en particular a lo dispuesto en los arts. 31 a 33 del Convenio de Viena de 23 de mayo de 1969 sobre el Derecho de los Tratados. En las relaciones con terceros Estados, los Estados miembros están obligados a acomodar su interpretación a estas reglas de Derecho internacional y no pueden invocar como elemento interpretativo ni las nociones autónomas del Derecho europeo ni las propias exigencias de coherencia del Derecho europeo. En cambio, cabe plantearse si el principio de coherencia y las nociones autónomas pueden ejercer su papel, y el TJUE requerirlo, cuando se trata de aplicar tales convenios en el marco de las relaciones entre Estados miembros. La base jurídica para ello la proporciona el propio art. 31.3.c) del Convenio de Viena, en la medida en que contempla como elemento a tener en cuenta en la interpretación toda norma pertinente de Derecho internacional aplicable entre las partes. El Derecho europeo, como orden jurídico propio de una organización internacional, debe ser considerado como Derecho internacional a los efectos de interpretación de los tratados; en particular, las exigencias del Derecho europeo puedan ser determinantes a la hora de establecer, en especial, el ámbito de aplicación en la Unión Europea de determinados tratados ${ }^{12}$. Fuera de estas cuestiones de compatibilidad o desconexión, en las relaciones intracomunitarias no parece concebible una interpretación diferenciada de convenios como los aprobados

12 La cuestión se ha suscitado, en particular, en relación con la aplicabilidad en el interior de la Unión Europea del Tratado sobre la Carta Europea de la Energía en el ámbito del arbitraje de inversiones en las relaciones intracomunitarias entre Estados miembros o relaciones inter se. Es un hecho que los tribunales de inversiones han establecido que el Derecho europeo forma parte del Derecho internacional y solo por esta razón sería ya relevante (véase BERMANN, G., «European Union law as a Jurisdictional and Substantive Defense in Investor-State Arbitration», European International Arbitration Review, 2017/2, pp. 51-58). La Comisión Europea, actuando como amicus curiae en muchos de estos arbitrajes de inversiones vinculados a los incentivos públicos a las energías renovables, ha mantenido la inaplicación de este Tratado en las relaciones intra-europeas. La posición de la Comisión se ha visto reforzada por la jurisprudencia del TJUE en el asunto Achmea (asunto 284/16, ECLI:EU:C:2018:158), que considera ineficaz el acuerdo arbitral contenido en un Tratado bilateral de protección de inversiones entre dos Estados miembros cuando la disputa afecta a un inversor de un Estado miembro frente a otro Estado miembro. La base jurídica para esta afirmación es esencialmente que el Derecho europeo puede ser interpretado y aplicado en tales procedimientos arbitrales, sin que por otra parte el tribunal arbitral pueda cursar o considerar oportuna una cuestión prejudicial, a diferencia de las jurisdicciones nacionales que se enmarcan en el sistema jurisdiccional de la Unión Europea y cuya intervención se orienta por el principio de confianza mutua. En suma, como reconoce el TJUE expresamente, el principio de coherencia está en la base de la polémica «doctrina Achmea»: «La piedra angular del sistema jurisdiccional así concebido es el procedimiento de remisión prejudicial contemplado en el art. 267 TFUE, que, al establecer un diálogo de juez a juez precisamente entre el Tribunal de Justicia y los órganos jurisdiccionales de los Estados miembros, tiene como finalidad garantizar la interpretación uniforme del Derecho de la Unión, permitiendo de ese modo asegurar su coherencia, su plena eficacia y su autonomía» (FJ 37). 
en la Conferencia de La Haya, que habilite una interpretación distinta de conceptos como la «residencia habitual», según que se aplique un Convenio de La Haya u otro en el ámbito intra o extracomunitario. La uniformidad en la interpretación de los tratados internacionales es un valor en sí mismo que no avala semejante esquizofrenia.

13. Por lo demás, en las relaciones transversales de fuentes normativas, las propias cláusulas de compatibilidad implican una evidente claudicación del principio de coherencia, que viene impuesta por el respeto a las obligaciones adquiridas con terceros Estados en virtud de previos compromisos convencionales. Basta señalar la pervivencia de los convenios de La Haya de 4 de mayo de 1971 sobre la ley aplicable en materia de los accidentes de circulación por carretera o de 2 de octubre de 1973 sobre la ley aplicable a la responsabilidad por productos. El art. 28 del Reglamento (CE) núm. 865/2007 relativo a la ley aplicable a las obligaciones extracontractuales («Roma II») habilita dicha compatibilidad, al igual que se ha mantenido en materia de competencia judicial internacional y reconocimiento de decisiones en los sucesivos textos «Bruselas». El resultado práctico de estos convenios no puede ser más desafortunado para la armonización, en particular cuando se trata de convenios sobre ley aplicable. Los convenios en materia procesal permiten diferenciar según que las relaciones sean intracomunitarias o extracomunitarias, desconectando la aplicación de sus normas en los supuestos intracomunitarios, pero la universalidad o carácter erga omnes que caracteriza las normas sobre Derecho aplicable conduce a resultados poco deseables: así, mientras que un tribunal inglés requerido como lugar del domicilio del demandado aplica a un accidente de circulación ocurrido en Alemania con partes británicas la ley aplicable que determina el reglamento «Roma II» ${ }^{13}$, los tribunales españoles aplicarán, a un accidente similar con partes española y domicilio del demandado en España, la ley que determina el Convenio de La Haya de 1971. Pero si el accidente ocurre en España y el demandado reside en el Reino Unido, la demanda puede presentarse indistintamente en España o en el Reino Unido sobre la base del reglamento "Bruselas I», pero la ley aplicable seguirá siendo diferente. No puede extrañar, por tanto, que el principio de coherencia requiera en estos casos de una actuación unilateral de los Estados parte de los Convenios de La Haya, procurando su denuncia ${ }^{14}$.

14. Mención aparte merece la particular relación transversal existente entre los reglamentos «Bruselas I» y «Bruselas I bis» y los convenios de Lugano I y Lugano $\mathrm{II}^{15}$. En apariencia, dado que tales textos se aplican en ám-

13 Es el caso Gaynor Winrow v. Ageas Insurance Ltd [2014] EWHC 3164 (QB). Véase nota de SÁNCHEz LoRenzo, S., Annuaire de droit de l'Union Européenne, 2014, pp. 478-485.

14 Véase Garau Juaneda, L., "La conveniencia de una denuncia por parte de España del Convenio de La Haya de 1971 sobre responsabilidad civil derivada de accidentes de circulación», AEDIPr., vol. VII, 2007, pp. 497-504.

15 La historia de esta relación transversal es significativa: el Convenio de Lugano de 16 de septiembre de 1988 relativo a la competencia judicial, el reconocimiento y la ejecución de resoluciones judiciales en materia civil y mercantil (Lugano I) se ratificó para extender inicialmente el espacio judicial europeo creado por el Convenio de Bruselas de 1968 a aquellos países que no siendo Estados miem- 
bitos territoriales y espaciales diferenciados, el desajuste o incoherencia no debería resultar problemático. Pero nada más lejos de la realidad. En esencia, el Reglamento 4/2009 no contiene reglas específicas de compatibilidad con el Convenio de Lugano. Con carácter general, el art. 69.1 del Reglamento prevé su compatibilidad con los acuerdos bilaterales y multilaterales vigentes, que pueden afectar a las relaciones de los Estados miembros con terceros Estados. Por otra parte, las reglas de compatibilidad del Convenio de Lugano con el régimen de Bruselas (art. 64 del Convenio), aplicables por analogía ${ }^{16}$ o por extensión ${ }^{17}$, sugieren que se apliquen las reglas del Convenio cuando exista sumisión a los tribunales de un Estado parte que no sea miembro de la Unión Europea (Suiza, Noruega o Islandia) o, en su defecto, el demandado se encuentre domiciliado en uno de estos Estados.

15. Estas reglas de delimitación no son, sin embargo, infalibles. Para ilustrar los desajustes, basta recordar ciertas dificultades para conjugar la aplicación del Reglamento (CE) núm. 4/2009 («Bruselas III») en materia de alimentos con las disposiciones del Convenio de Lugano $\mathrm{II}^{18}$. Por otra parte,

bros de las Comunidades Europeas participaban de la Asociación Europea de Libre Cambio. Acabaría sirviendo, asimismo, para la adhesión de Estados que se aproximaban desde el Este como candidatos firmes a incorporarse a la Unión (Polonia). La «comunitarización» del Convenio de Bruselas y su conversión en el Reglamento 44/2001 provocó un divorcio o desajuste que tuvo que ser remediado con la renovación por el Convenio de Lugano de 30 de octubre de 2007 del mismo nombre («Lugano II»), circunstancia que permitió al TJUE incidir en la competencia exclusiva de la Comunidad Europea para su celebración [Dictamen 1/03 del TJUCE (Pleno) de 7 de febrero de 2006]. Pero apenas este Convenio empezó a funcionar, el Reglamento 1215/2012 (Bruselas I bis) dio al traste con la convergencia y provocó la necesidad de un próximo «Lugano III». Ciertamente, las velocidades nomogenéticas no son las mismas en un proceso de negociación de un convenio internacional que en una acción institucional de la Unión Europea. Por ello, es previsible que «Lugano III» llegue al mismo tiempo que se sustituye «Bruselas I bis» por un hipotético «Bruselas I ter».

16 Véase en este sentido ANDRAE, M., «EGUnt-VO», Europäisches Zivilprozessrecht und Kollisionsrecht EuZPR/EuIPR Kommentar (T. Rauscher Hrg.), Munich, Sellier, 2010, p. 756.

17 Así lo afirma la STJUE (Sala 2. ${ }^{\text {a }}$ ) de 20 de diciembre de 2017 (asunto C-467/16. Brigitte Schlömp/ Landratsamt Schwäbisch Hall), en sus fundamentos 41 a 43 (ECLI:EU:C:2017:993).

18 El Reglamento «Bruselas III" contempla la prorrogatio fori, de forma que permite a las partes acordar por escrito, con carácter general, la competencia «exclusiva», salvo pacto en contrario, de los Tribunales del Estado miembro de la residencia habitual o de la nacionalidad (domicile en el caso del Reino Unido e Irlanda) de cualquiera de las partes (art. 4). Esta posibilidad se extiende, en el caso de cónyuges y excónyuges, a los órganos jurisdiccionales que resulten competentes para conocer de la causa matrimonial de conformidad con el Reglamento «Bruselas II bis» o a los coincidentes con su última residencia habitual común durante al menos un año. Los foros señalados deben concurrir bien en el momento de celebrarse el acuerdo de elección de fuero, bien en el momento de presentar la demanda. La posibilidad de sumisión expresa resulta excluida cuando se trata de obligaciones alimenticias respecto de menores de dieciocho años (art. 4.3). Pues bien, si el acuerdo de las partes designa la competencia exclusiva de los órganos jurisdiccionales de un Estado parte del Convenio «Lugano II», que no sea Estado miembro de la Unión Europea (Suiza, Noruega o Islandia), la competencia se determinará de conformidad con el Convenio «Lugano II». El problema que se plantea es si dicha sumisión en favor de unos tres Estados se refiere a las obligaciones alimenticias respecto de menores de dieciocho años, en que según el Reglamento la prorrogatio fori no está reconocida. En tales circunstancias, si se descarta la prorrogatio fori y se aplican los foros de competencia del Reglamento previstos en su defecto, se plantearía una interferencia del legislador europeo en las opciones de sumisión que sí habilita el art. 23 del Convenio «Lugano II» [véanse ÁlVAREZ GonZÁLEZ, S., «El Reglamento 4/2009 CE sobre obligaciones alimenticias: cuestiones escogidas», Revista Jurídica Española La Ley, 31 de julio de 2009, núm. 7.230, pp. 2-3; RUEDA VALDIVIA, R., «Cambios en el sistema de fuentes de Derecho internacional privado en materia de alimen- 
aun en los ámbitos bien delimitados, el paralelismo de unas normas pensadas para extender un espacio judicial europeo requiere una interpretación uniforme que no puede ser garantizada conforme a las reglas que caracterizan a la transversalidad de fuentes. De ahí que la solución se haya alcanzado en este caso concreto a través del propio Protocolo núm. 2 al Convenio de Lugano, relativo a la interpretación judicial uniforme del Convenio y al Comité Permanente, que permite extender de facto la función interpretativa del Tribunal de Justicia de la Unión Europea.

\section{LAS DIFICULTADES DE UNA INTERPRETACIÓN SISTEMÁTICA SIN SISTEMA: EL MITO DE LAS NOCIONES AUTÓNOMAS}

16. Hemos definido el principio de coherencia como un instrumento esencialmente orientado a una interpretación sistemática del Derecho internacional privado europeo. Sin embargo, la pretensión es en sí misma paradójica. El Derecho internacional privado europeo es una rama del ordenamiento jurídico, inseparable de hecho, cuando menos, del Derecho privado en su conjunto. Aunque la evolución del Derecho internacional privado europeo ha sido imparable, y hoy por hoy cubre una buena parte del Derecho internacio-

tos», El arreglo pacífico de controversias internacionales (XXIV Jornadas de la Asociación Española de Profesores de Derecho Internacional y Relaciones Internacionales - AEPDIRI. Córdoba, 20-22 de octubre de 2011), Valencia, Tirant lo Blanch, 2013, p. 610]. En defecto de sumisión expresa o tácita, el Reglamento «Bruselas III», de forma parecida a lo previsto en el Reglamento «Bruselas I» o en el Convenio «Lugano II", prevé la competencia concurrente de los tribunales de los Estados miembros correspondientes a la residencia (en lugar del domicilio) del demandado y a la residencia (y no al domicilio) del acreedor de alimentos [art. 3.a) y b)]. Aparentemente, la regla citada facilita la compatibilidad del Reglamento con el Convenio «Lugano II». Si el demandado tiene su domicilio en un Estado miembro o en un tercer Estado, no debe existir problema en aplicar los foros de competencia del Reglamento. Sin embargo, la situación puede ser más dudosa si, por ejemplo, el domicilio del demandado se encuentra en un Estado parte del Convenio «Lugano II», no miembro de la Unión Europea. Según las reglas de compatibilidad entre el Convenio «Lugano II» y el Reglamento «Bruselas I» [art. 64.2.a) del Convenio], en este caso las normas de competencia aplicables deberían ser las de los arts. 3 y 5.2 del Convenio «Lugano II», que no son exactamente coincidentes, pues se refieren al «domicilio» del demandado o al «domicilio o residencia habitual» del acreedor de alimentos. No existe una regla de compatibilidad específica en este punto entre el Reglamento «Bruselas III» y el Convenio «Lugano II», con excepción de la regla general del art. 69 del Reglamento «Bruselas III»; lo más lógico será mantener, pues, el mismo criterio de compatibilidad. Aunque en la práctica es difícil que se susciten conflictos, debe tenerse en cuenta que mientras la «residencia habitual» es un concepto europeo autónomo, el «domicilio» depende de los sistemas jurídicos nacionales (art. 59 del Convenio Lugano II). Esto quiere decir que es factible que, aplicando la ley nacional, se considere que el domicilio del acreedor o deudor de alimentos demandado se encuentra en Suiza, Noruega o Islandia y, al mismo tiempo, utilizando el concepto autónomo de «residencia habitual» se estime que esta se encuentra ubicada en un Estado miembro. En tal caso, es fácil que el tribunal del Estado miembro en que reside el demandado tienda a declararse competente en virtud de lo dispuesto en el art. 3.a) del Reglamento, cuando en puridad las reglas aplicables resultan ser las del Convenio de Lugano II en virtud del domicilio del demandado [art. 64.2.a)], que precisamente utilizan como foro general dicho «domicilio» (art. 2), lo que justificaría, a salvo de foros especiales, la competencia del tribunal suizo, islandés o noruego donde se estima que el demandado tiene su domicilio. Este último ejemplo nos conduce, en realidad, a un problema más general, fuente de múltiples incoherencias, que enfrenta la autonomía de los conceptos fácticos a la nacionalidad de los conceptos jurídicos y que será analizado con detalle más adelante. 
nal privado de los Estados miembros, el hecho es que no existe un sistema de Derecho privado europeo ni una armonización relevante en este ámbito, como hemos puesto de relieve en otros lugares ${ }^{19}$. En consecuencia, mientras el Derecho internacional privado cae bajo la competencia más amplia de la armonización europea, el Derecho privado se mantiene en la órbita de los Derechos nacionales, fuertemente impermeable a la armonización europea. Esta circunstancia ha lastrado la propia armonización del Derecho internacional privado, multiplicando sus imperfecciones y, en consecuencia, los riesgos de incoherencias difícilmente solubles ${ }^{20}$. En buena medida, el Derecho internacional privado europeo adolece de falta de solidez sistemática.

\footnotetext{
19 Véase Sánchez Lorenzo, S., Derecho privado europeo, Comares, 2002, pp. 193-292.

20 Por otra parte, la armonización del Derecho internacional privado no ha podido prescindir de los lastres que caracterizaban las soluciones convencionales o intergubernamentales. Hay, en los reglamentos europeos, demasiadas concesiones o soluciones transaccionales. Un buen ejemplo puede ser la imperfección que deriva del ámbito de aplicación del Reglamento «Roma II» al excluir los daños producidos por violación de la intimidad o de los derechos de la personalidad. Es bien sabido que esta exclusión obedeció al deseo de que el Reino Unido, como así fue, participara en el Reglamento. La reticencia de los demás Estados a incluir la regla británica de la «double actionability», que satisface a los potentes lobbies de la comunicación en el Reino Unido, aconsejaba una prudente exclusión. Tras el Brexit, ya se anuncia una reforma del Reglamento para incluir la materia excluida por motivos transaccionales. El elemento transaccional está presente asimismo en claras involuciones de contenido, como la que se puede apreciar en el tratamiento de las leyes de policía de terceros Estados si comparamos el art. 7 del Convenio de Roma y el art. 9 del Reglamento "Roma II» (nos remitimos a las consideraciones críticas que vertimos en SÁNCHEz Lorenzo, S., "Choice of Law and Overriding Mandatory Rules in International Contracts after Rome I», Yearbook of Private International Law, vol. 12, 2010, pp. 81-86). La restricción de los supuestos en el Reglamento fue igualmente un guiño al Reino Unido, que había reservado la aplicación del art. 7.1 del Convenio de Roma, para que se sumara al Reglamento, como así fue. La consecuencia fue una limitación injustificada de la aplicación de normas imperativas de terceros Estados distintos a los del lugar de ejecución del contrato, tales como las del Estado de origen en caso de comercio de bienes culturales, las del Estado de establecimiento de la sociedad en relación con ciertas actividades sujetas a autorización o conductas medioambientales o sanitarias, o las del Estado cuyo mercado resulta afectado sin ser el de ejecución del contrato en supuestos de infracción de normas sobre la competencia. Aunque tal vez lo más paradójico del caso es que el Derecho internacional privado inglés, aun aplicando el Reglamento «Roma I», es capaz de aplicar estas normas internacionalmente imperativas de terceros Estados distintos al país de la ejecución a partir de la noción de comity y de la cláusula general de orden público (véase, para más detalle, SÁNchez LoRENzo, S., El Derecho inglés y los contratos internacionales, Valencia, Tirant lo Blanch, 2003, pp. 159-162). Las distintas velocidades constitucionales, con las facultades de Dinamarca, Irlanda y el Reino Unido, han contribuido, asimismo, a la incoherencia normativa, que dificulta la coherencia interpretativa. Este Derecho internacional privado a distintas velocidades afecta, como es sabido, a ámbitos del Derecho de familia como los Reglamentos «Roma III» y los referidos a los regímenes económicos matrimoniales o de las parejas registradas, además de a otros en los que se detecta la ausencia del Reino Unido o Dinamarca. El efecto producido recuerda, mutatis mutandis, a los perniciosos efectos para el Derecho privado europeo de las denominadas «directivas de mínimos» o de armonización mínima, que, por ejemplo, establecen un marco común de protección habilitando a los Estados, al mismo tiempo, para aumentar dicho umbral. La consecuencia final es la misma: un Derecho internacional privado deforme (remedando a FERRARA, F., «La lege difforme cambiaria», Scritti Minori, t. III: Titoli di crédito. Le Banche e le operazioni di banca, Milán, 1971, pp. 41-81), más que uniforme, que al final provoca impredecibilidad y complejidad. Los riesgos de las directivas de mínimos ya fueron advertidos por las instituciones europeas desde un inicio. Como señalaba el Comité Económico y Social, en relación con la Directiva 93/13/CEE (cláusulas abusivas): «Se mantienen diferencias notables en los niveles de protección de los consumidores, facilitadas por el carácter minimalista de la Directiva, que permite que determinados Estados miembros instituyan regímenes más estrictos — pero no armonizados- de protección de los consumidores, lo que no contribuye a la realización del mercado interior, sino que más bien la perjudica» [Dictamen del
} 
17. El argumento se vincula en primer término a la ausencia de una auténtica «Parte General» del Derecho internacional privado y entronca con las conocidas reivindicaciones, bastante quiméricas, orientadas a la redacción de Reglamentos «Bruselas-0» y «Roma-0», o de un Código europeo de Derecho internacional privado ${ }^{21}$. Hasta cierto punto es incorrecto pensar que el Derecho internacional privado europeo no alcanza en modo alguno a una «parte general» del Derecho internacional privado. Al menos, muchos de los problemas generales de la competencia judicial internacional (litispendencia, conexidad, sumisión tácita, control de oficio) y de Derecho aplicable (normas imperativas, orden público, remisión a sistemas plurilegislativos, reenvío) tienen una reglamentación clara en los distintos textos, variable en algunos casos, pero no exenta de cierta coherencia. En el ámbito del reconocimiento y ejecución de decisiones y actos la inducción de una auténtica parte general es más evidente y se antoja menos necesaria. Pero también es cierto que esa ausencia de Parte General debilita en muchos casos el efecto útil de la armonización. El ejemplo más evidente viene dado por la diversidad de sistemas nacionales en el mecanismo de alegación, prueba y aplicación del Derecho extranjero ${ }^{22}$. De poco sirve implementar normas de Derecho aplicable comunes, si no se garantiza una aplicación de oficio del Derecho extranjero o se facilita procesalmente el legeforismo con una aplicación «residual» de la lex fori más común de lo deseable. No mejora el problema el hecho de que el conocimiento e información del Derecho extranjero, en particular de los propios Estados miembros, haya empeorado en los últimos tiempos, por la vía de eliminar el cauce de la cooperación consular sobre la falsa hipótesis de la accesibilidad al Derecho de otros Estados miembros mediante las redes judiciales y mecanismos propiamente europeos, de todo punto insuficientes.

18. En todo caso, las imperfecciones del sistema de Derecho internacional privado europeo (y el hecho cierto de un no-sistema de Derecho privado

Comité Económico y Social sobre el tema «Informe de la Comisión sobre la aplicación de la Directiva 93/13/CEE, del Consejo, de 5 de abril, sobre las cláusulas abusivas en los contratos celebrados con consumidores» (DOCE C 116, de 20 de abril de 2001, pp. 117-127)]. El mismo resultado se obtiene en aquellas Directivas que, sin pretender una armonización mínima, introducen posibilidades de excepción por razones de orden público o moralidad. Es el caso del art. 6 de la Directiva 98/44/CE, del Parlamento Europeo y del Consejo, de 6 de julio, relativa a la protección jurídica de las invenciones biotecnológicas, que excluye la patentabilidad de las invenciones cuya explotación comercial sea contraria al orden público o a la moralidad, interpretadas de forma discrecional por las autoridades nacionales en el contexto social y cultural de cada Estado miembro (STJCE de 9 de octubre de 2001, asunto C-377/98, Países Bajos/Parlamento, ECLI:EU:C:2001:523).

21 Véanse LeIble, S. y UnBerath, H. (eds.), Brauchen Wir ein Rome-O Verordnung?: Überlegunguen zu einem Allgemeinen Teil des europäischen IPR, Jena, JWV, 2013; LEIBLE, S. y MÜLLER, M., "A General Part for European Private International Law? The Idea of a Rome 0 Regulation», Yearbook of Private International Law, vol. 14 (2012-2013), pp. 137-152; LAGARDE, P., «Embryon de règlement portant Code européen de droit international privé», Rabels Z., vol. 75, 2011, pp. 673-676; FALLON, M., LAGARDE, P. y Poillot-Peruzzetto, S. (dirs.), Quelle architecture pour un code européen de droit international privé, Bruselas, Peter Lang, 2011.

22 Véanse las demoledoras conclusiones del informe de Esplugues Mota, C., «General Report on the Application of Foreign Law by Judicial and Non-Judicial Authorities in Europe», en EsPLUGUES Mota, C., Iglesias Buhigues, J. L. y Palao Moreno, G. (eds.), Application of Foreign Law, Munich, Sellier, 2011, pp. 3-94, esp. pp. 90-91. 
europeo) cargan en las espaldas del intérprete una labor interpretativa hercúlea. Con los imperfectos mimbres que le proporciona el legislador europeo, el TJUE actúa como una especie de juez inglés creando reglas de common law en ausencia de Derecho escrito. El inconveniente es que el TJUE se compone de aficionados en el campo del Derecho privado y, por supuesto, en el Derecho internacional privado. La mayor parte de jueces y abogados generales son especialistas de Derecho público o Derecho internacional público: internacionalistas, constitucionalistas y administrativistas. Su competencia queda fuera de duda cuando se trata de aplicar e interpretar el Derecho institucional, pero a menudo resulta muy dudosa al enfrentarse a principios y razonamientos de puro Derecho privado, como tendremos ocasión de evidenciar. Las instituciones europeas deben afrontar la necesidad de especializar las Salas del TJUE y, en particular, se hace necesaria una Sala que extienda su competencia a los sectores más vinculados al Derecho privado ${ }^{23}$, tales como la cooperación judicial en materia civil o la política de consumidores.

19. Con todo, la labor del TJUE es limitada; y es un hecho contrastado que los órganos jurisdiccionales nacionales, e incluso las propias partes, son reacias a sufrir las demoras que provoca la interposición de una cuestión prejudicial. Con excesiva frecuencia, los tribunales nacionales se arriesgan a interpretar el Derecho internacional privado aun cuando su alcance o el problema planteado disten mucho de poder calificarse como claros. Es paradigmática en este sentido la diversidad de interpretaciones por los jueces nacionales acerca de la posibilidad de una elección tácita de la ley aplicable prevista en el art. 3 del Reglamento "Roma I» ${ }^{24}$. Como expusimos en otro lugar ${ }^{25}$, la divergencia en la interpretación de esta peculiar cuestión viene dada de forma inevitable por un círculo vicioso. Inducir una elección de la ley aplicable en virtud de una voluntad tácita exige aplicar reglas de interpretación del contrato, que difieren de un Estado a otro. Si la interpretación del contrato se rige por la lex contractus, ¿cómo podemos resolver la cuestión si aún no sabemos cuál es la lex contractus? La solución es sencilla: cada juez aplica su propio Derecho contractual o lex fori y las soluciones finales sobre la lex causae son divergentes. De esta forma, la coherencia exige, como advierte el TJUE en el caso Achmea, hacer de la cuestión prejudicial la clave de bóveda del principio. Pero siendo este un postulado, aún queda por ver en qué medida el TJUE, incluso sirviéndose de jueces y abogados generales expertos en Derecho privado e internacional privado, puede ser capaz, sin contar con un sistema de Derecho privado, de crear un catálogo de nociones autónomas de

${ }^{23}$ Véase en este sentido LeIBLE, S., «Die Rolle der Rechtsprechung der Europäischen Gerichtshofes bei der europäischen Privatrechtsentwicklung», Auf dem Wege zu einem europäischen Zivilgesetzbuch, Frankfurt, Springer, 1999, pp. 59 y 80-83.

${ }^{24}$ Véanse Plender, R. y Wilderspin, M., The European Contracts Convention: The Rome Convention on the Law Applicable to Contractual Obligations, 2. ${ }^{a}$ ed., Londres, Sweet \& Maxwell, 2001, pp. 92100; WildersPin, M., «Les perspectives d'une révision de la convention de Rome sur la loi applicable aux obligations contractuelles», Les conflits de lois et le système juridique communautaire, París, Dalloz, 2004 , p. 177.

${ }_{25}$ Véase SÁnchez Lorenzo, S., «Choice of Law...», loc. cit., op. cit., nota 20, pp. 79-81. 
Derecho internacional privado o instrumentales para la interpretación de las normas de Derecho internacional privado ${ }^{26}$. Como veremos, la posibilidad de generar nociones autónomas en el marco europeo, constantemente reivindicada por el TJUE, es limitada, de forma que la invocación de este principio pertenece más al mito que a la realidad.

20. Los conceptos autónomos son posibles y funcionan eficientemente cuando se trata de datos o elementos fácticos, incluso con relevancia jurídica. Así, es posible un concepto europeo de "residencia habitual», aunque pueda ser variable según los ámbitos materiales. Si se trata de determinar la residencia habitual del menor a efectos de la competencia judicial internacional en materia de responsabilidad parental (art. 8 del Reglamento «Bruselas II»), el concepto se orientará a la acotación de las circunstancias de la permanencia del menor en un territorio que apunten a la determinación de su entorno social y familiar ${ }^{27}$. El concepto puede resultar muy próximo al de la residencia habitual en materia sucesoria o alimenticia, con las debidas matizaciones en razón de las peculiaridades de la materia y de los objetivos de política legislativa que persigue el foro en cada caso, pero lo relevante es que el TJUE, una vez determinado ese objetivo, juega esencialmente con elementos fácticos para elaborar una noción autónoma: duración, regularidad, condiciones y razones de permanencia en el territorio de un Estado miembro y del traslado de la familia a dicho Estado, nacionalidad del menor, lugar y condiciones de escolarización, conocimientos lingüísticos, relaciones familiares y sociales en dicho Estado, compra un alquiler de vivienda por los padres o solicitud de una vivienda social, etc. La ausencia de un Derecho privado europeo no es un obstáculo insalvable, pues la creación del concepto autónomo puede prescindir de la forma diferente en que se entiende el concepto de residencia habitual en los distintos ordenamientos jurídicos: a lo sumo, existirá una diferencia de criterio en la apreciación de circunstancias fácticas o del modo en que se orienta el propio concepto.

21. La misma facilidad para alcanzar una noción autónoma de contenido fáctico se encuentra al determinar el concepto de «lugar de entrega» 0 «lugar de prestación del servicio» en materia de obligaciones contractuales. En el primer caso, la circunstancia fáctica retenida atiende al lugar en que la entrega material se efectuó o debía efectuarse y en virtud de la cual el comprador adquiere la facultad de disponer efectivamente de tales mercancías en el destino final de la operación de compraventa ${ }^{28}$. En el segundo, el TJUE ha tendido hacia el lugar de prestación «principal» o «efectiva», estableciendo

26 Sobre las nociones autónomas, véanse RIESENHUBER, K., «§ 10. Die Auslegung», Europäische Methodenlehre, 3. ${ }^{\mathrm{a}}$ ed., Berlín, De Gruyter, 2015, pp. 201-202. Id., «§ 10. Interpretation of EU Secondary Law», European Legal Methodology, Cambridge, Intersentia, 2017, pp. 233-235; MARMISSE-D'ABBADIE D'Arrast, A., "Qualification et concepts autonomies dans l'élaboration d'un code européen de droit international privé», Quelle architecture pour un code européen de droit international privé, Bruselas, Peter Lang, 2011, pp. 319-326.

27 STJCE (Sala 3. ${ }^{\text {a) }}$ de 2 de abril de 2009 (asunto C-523/07, A, ECLI:EU:C:2009:225).

28 STJUE (Sala 4. ${ }^{\text {a) }}$ ) de 25 de febrero de 2010 (asunto C-381/08, Car Trim GmbH/KeySafety Srl, ECLI:EU:C:2010:90). 
criterios subsidiarios en caso de duda, tales como el domicilio del agente ${ }^{29}$, o habilitando reglas para el caso de multiplicidad de lugares de entrega o prestación de servicios ${ }^{30}$. Tampoco habría sido particularmente complejo elaborar una presunción autónoma europea en relación con el lugar del pago, aunque la jurisprudencia del TJUE haya incorporado a cada caso la presunción, potencialmente diversa, prevista en la lex contractus ${ }^{31}$.

22. El foro especial en materia de responsabilidad extracontractual es asimismo representativo de las posibilidades positivas de construcción de nociones autónomas. La jurisprudencia del TJUE en este punto ha partido de un valor negativo para proporcionar una noción autónoma del lugar de daño: la ausencia de un principio de favor laesi ${ }^{32}$. Sobre esta base ha construido la noción a partir de un análisis estricto del principio de proximidad definido a partir de ventajas en la organización del proceso, ya sea para determinar la culpabilidad o el daño. A partir del asunto Minas de Potasa ${ }^{33}$, el TJUE ha dictado múltiples decisiones cuya función ha sido acotar, precisamente, la circunstancia fáctica del elemento causal o del lugar de producción del daño aplicado a diversos ámbitos y sectores.

23. La posibilidad de proporcionar nociones autónomas queda, sin embargo, en entredicho, cuando más allá de las circunstancias fácticas determinantes de la precisión de un foro o punto de conexión de carácter fáctico, el TJUE no se limita a determinar la relevancia jurídica de los hechos o, dicho de otra manera, la elevación de una circunstancia fáctica al orden de los conceptos jurídicos, sino que debe lidiar con conceptos o nociones propiamente jurídicas, que implican una clara pre-comprensión por parte de los sistemas jurídicos. En estos casos, sin un Derecho privado propiamente europeo, no es verosímil que pueda definirse en términos europeos qué es «materia contractual» $\mathrm{O}$ «extracontractual», «enriquecimiento injusto» $\mathrm{O}$ «buena fe».

24. La historia del fracaso en la delimitación de la materia «contractual» o «extracontractual» en el marco del Reglamento «Bruselas I» (y «Bruselas I bis») es reveladora a este respecto. La calificación contractual requería la exis-

29 STJUE (Sala 3. a) de 11 de marzo de 2010 (asunto C-19/09, Wood Floor Solutions Andreas Domberger GmbH c. Silva Trade SA, ECLI:EU:C:2010:137); STJUE (Sala 3. ${ }^{\text {) }}$ ) de 10 de septiembre de 2015 (asunto C-47/14, Ferho, ECLI:EU:C:2015:574); STJUE (Sala 7. ${ }^{\text {) }}$ de 8 de marzo de 2018 (asunto C-64/17, Saey Home \& Garden NV/SA c. Lusavouga-Máquinas e Acessórios Industriais SA, ECLI:EU:C:2018:173).

30 STJCE de 3 de mayo de 2007 (asunto C-386/05, Color Drack, ECLI:EU:C:2007:262); STJCE $\left(\right.$ Sala 4. ${ }^{\text {a) }}$ ) de 9 de julio de 2009 (asunto C-204/08, Rehder, ECLI:EU:C:2009: 439); STJUE (Sala 3. ${ }^{\mathrm{a}}$ ) de 7 de marzo de 2018 (asuntos C-274/16, 447/16 y 447/18, flightright GmbH/Air Nostrum, Roland Becker/ Hainan Airlines y Barkan y otros/Air Nostrum, ECLI:EU:C:2018:160).

31 STJCE de 6 de octubre de 1976 (asunto 12/1976, Tessili/Dunlop, ECLI:EU:C); STJCE de 26 de junio de 1994 (asunto C-288/1992, Custom Made Commercial Ltd/Stawa Metallbau GmbH, ECLI:EU:C:1994:268); STJCE de 28 de septiembre de 1999 (asunto C-440/1997, Concorde, ECLI:EU:C:1999:456); STJCE de 5 de octubre de 1999 (asunto C-420/1997, Leathertex Divisione Sintetici SpA/Bodetex BVBA, ECLI:EU:C:1999:483); STJUE (Sala 1. a) de 14 de marzo de 2013 (asunto C-419/11, Česká spoçiteln, ECLI:EU:C:2013:165).

32 STJUE (Sala 1. ${ }^{\text {a }}$ ) de 25 de octubre de 2012 (asunto C-133/11, Folien Fischer Fofitec/Ritrama SpA, ECLI:EU:C:2012:664).

33 STJCE de 30 de noviembre de 1976 (asunto 21/1976, Mines de Potasse d'Alsace). 
tencia de una obligación libremente acordada entre las partes ${ }^{34}$. La ausencia de dicha obligación implicaba la calificación no contractual de la responsabilidad derivada de un hecho ilícito propiamente dicho o de la vulneración de una obligación legal en materia de propiedad industrial o intelectual, libre competencia o fraude fiscal. La dificultad, evidentemente, radica en calificar la acción o el derecho en aquellos casos en que existiendo una obligación contractual, libremente consentida por las partes, se dilucida una responsabilidad eventualmente extracontractual. El primer tropezón de cierto calibre se produce en la solución del asunto Brogsitter ${ }^{35}$. En el caso concreto, la acción se fundó en el Derecho alemán sobre competencia desleal con el objeto de reclamar la responsabilidad extracontractual derivada de la comercialización de mecanismos de relojería por parte del relojero que se había comprometido contractualmente a fabricar dichos mecanismos para el demandante, presuntamente en virtud de un pacto que implicaba exclusividad. La pretensión del TJUE de elaborar una delimitación autónoma de la materia contractual y extracontractual le impelía a partir de una calificación ajena a la configuración o base legal de la acción en los Derechos nacionales. El TJUE invocó la necesidad de «interpretar el contrato» en la calificación contractual, de forma que se trataría de materia contractual «si la interpretación del contrato que une al demandado con el demandante resulta indispensable para determinar la licitud o, por el contrario, la ilicitud del comportamiento imputado al primero por el segundo». El argumento conduce al absurdo. La interpretación del contrato puede ser necesaria para determinar el incumplimiento de una obligación contractual, pero también puede ser determinante para establecer la existencia de una obligación de exclusividad que puede condicionar un supuesto de competencia desleal ilícita. Pero, lo que es más evidente, interpretar un contrato no es una mera cuestión de hecho, sino de Derecho, que depende de la ley que rige el contrato [art. 12.1.a) del Reglamento «Roma I»]. En todos los sistemas jurídicos, el contrato no solo obliga a lo que las partes han convenido, sino a las obligaciones legales (no convenidas) previstas por la ley rectora del contrato o, incluso, por la ley de un tercer Estado (art. 9 del Reglamento «Roma I») ${ }^{36}$. Se trata de obligaciones contractuales que no emanan del contrato, sino del Derecho de los contratos, y cuya exigencia o incumplimiento no requieren de la interpretación del contrato, sino de la Ley ${ }^{37}$. Del mismo modo, la equidad o la buena fe son, en muchos, aunque no en todos los sistemas, fuentes de obligaciones contractuales externas al propio contrato.

25. En suma, para la calificación contractual la necesidad de interpretar el contrato no es operativa ni determinante. El TJUE puede intentar

34 STJCE de 17 de junio de 1992 (asunto C-26/1991, Handte, ECLI:EU:C:1992:268); STJUE (Sala 7. ${ }^{\text {a) }}$ de 17 de octubre de 2013 (asunto C- 519/12, OTP Bank, ECLI:EU:C:2013:674).

35 STJUE (Sala 7. ${ }^{\text {) }}$ ) de 13 de marzo de 2014 (asunto C-548/12, Brogsitter, ECLI:EU:C:2014:148). p. 108.

36 Véase, en este sentido, la Nota de AfFerinI, G., European Review of Contract Law, vol. 1, 2005/1,

37 Véase DoRnIs, T. W., «Von Kalfelis zu Brogsitter - Künftig enge Grenzen der Annexkompetenz in europäisches Vertrags- un Deliktsgerichtsstand», Zeitschrift für das Privatrecht der Europäischen Union, 6/2014, pp. 352, 354 . 
calificar la naturaleza de la relación jurídica a partir de criterios sustanciales autónomos, y en ocasiones tales criterios existen en el Derecho europeo. Así ocurre con la calificación contractual de la restitución del pago en caso de nulidad del contrato en razón del propio art. 12.1.e) del Reglamento "Roma $I »{ }^{38}$, pero en general es una labor imposible en ausencia de un Derecho privado europeo ${ }^{39}$. La alternativa, pues, obliga a tener en cuenta cómo se configura la causa petendi conforme al Derecho nacional en que se funda la acción, renunciando a una noción propiamente autónoma de «materia contractual», cosa que por otra parte ha hecho el propio TJUE en alguna ocasión ${ }^{40}$. De otra forma, el TJUE o, de forma más comprometida aún, las jurisdicciones nacionales deben dilucidar si el incumplimiento de la obligación (explícita o implícita) de exclusividad es una vulneración del contrato o una violación de las condiciones de protección del mercado en condiciones de competencia leal, sin que se vea muy bien con qué herramientas se puede llegar a una u otra conclusión en ausencia de un Derecho privado europeo.

26. Al hilo del asunto Brogsitter, me atreví a profetizar que algún día el TJUE se perdería en un caso de ruptura abrupta de las relaciones comercia$\mathrm{les}^{41}$, y ese día llegó casi de forma inmediata en el asunto Granarolo ${ }^{42}$. La ruptura abrupta de las relaciones comerciales cuando el contrato no contempla reglas de terminación merece una calificación contractual en sistemas como el español, el alemán o el inglés. Pero la eventual necesidad de un preaviso no emana del contrato, ni siquiera de la Ley, sino de la buena fe que, como la equidad, en algunos sistemas es una fuente autónoma de obligaciones contractuales (art. 1.258 del CC). La fuente de la responsabilidad no es el contrato, sino el Derecho contractual. En el Derecho inglés, aunque la materia sea contractual, simplemente se admite el derecho a romper abruptamente

${ }^{38}$ Cabe recordar a estos efectos la reserva realizada por el Reino Unido a la aplicación del art. 10.1.e) del Convenio de Roma.

39 Véase, en este sentido, la Nota de SuJEcKI, B., EuZW, 10/2014, pp. 384-385.

40 «En cuanto al fundamento jurídico de la demanda formulada por los Commissioners, la acción ejercitada por estos contra Sunico se basa, no en la legislación del Reino Unido en materia de IVA, sino en la presunta participación de Sunico en una conspiración para defraudar a la que se aplica el Derecho de ese Estado miembro sobre responsabilidad civil delictual o cuasidelictual» [STJUE (Sala 3. ${ }^{\text {a }}$ ) de 12 de septiembre de 2013 (asunto 49/12, Sunico, ECLI:EU:C:2013:545, pt. 37)].

41 «On peut se demander ainsi si la rupture brutale des relations commerciales sans aucun préavis donne lieu à une action contractuelle ou délictuelle. Selon le droit anglais (et la plupart des systèmes juridiques européens) il faudra interpréter le contrat afin de déterminer l'existence d'une obligation contractuelle implicite. Le droit anglais qualifierait la question comme contractuelle, interprétant le contrat et concluant que le préavis n'est pas en réalité un implied-in-fact term. Des systèmes juridiques, tels l'allemand ou l'espagnol, ont également besoin d'interpréter le contrat, mais ils arriveront peut-être à la conclusion de l'existence d'une obligation implicite imposée par le principe contractuel de la bonne foi. Par contre, même si la considération en France était purement délictuelle sur la base de l'article L 442-6-1, $5 .^{\circ}$ du Code de commerce, on peut tout de même compter avec une interprétation du contrat, surtout compte tenu du fait que les parties ont toujours l'option d'une action contractuelle» (SÁNCHEZ LoRENZO, S., "Délimitation ente "matière contractuelle" et "matière délictuelle" dans l'Espace judiciaire européen", Annuaire de droit de l'Union Européenne, 2014, pp. 476-477).

${ }_{42}$ STJUE (Sala 2. ${ }^{\text {a }}$ ) de 14 de julio de 2016 (asunto C-196/15, Granarolo SpA/Ambrosi Emmi France SA, ECLI:EU:C:2016:559). 
los contratos, si las partes no han previsto nada ${ }^{43}$. En cambio, en el Derecho francés la calificación es extracontractual, y la obligación de preaviso emana de la obligación legal dispuesta en el art. L-442-6-1-5 del CCo.

27. Para solucionar el problema, a través de un concepto autónomo, el TJUE se saca de la chistera la calificación contractual si es que existe una obligación implícita o tácita de preaviso. Para lograr su calificación autónoma, el TJUE convierte en un hecho una cuestión que es de Derecho: la interpretación jurídica. Con ello acredita su condición de diletante en materia de Derecho privado. En efecto, la existencia de una obligación tácita no es una cuestión de hecho, sino de Derecho, de interpretación del contrato, y para determinarla hay que aplicar alguna ley. En el caso de la ruptura abrupta, la ley española dice que la obligación tácita existe, por imponerla la buena fe; el Derecho inglés, que no existe porque el preaviso no es un implied-in-fact term. Y el Derecho francés, que ni falta que hace, porque es una obligación legal cuya invocación ha de ser extracontractual. Si pretendemos una calificación autónoma que no se sirva de las distintas opciones nacionales, la solución es fácil: para interpretar si hay una obligación tácita, apliquemos las reglas de interpretación (integración) del contrato del Derecho privado europeo, y no los Derechos nacionales. El TJUE propone algunos indicios, incluida la buena fe, como si se tratara de una cuestión puramente fáctica. Tales indicios son casi insultantes para el Derecho contractual inglés, y el TJUE se convierte de esta forma en legislador del Derecho contractual europeo formulando una aparente teoría general de la interpretación en Derecho de los contratos. Pero no existe un Derecho privado europeo al respecto, a menos que los Principios Lando o el Draft Common Law of Reference hayan entrado en vigor sin que lo hayamos advertido; ergo estamos como al principio y la solución es imposible en los términos que la plantea el TJUE.

28. La solución es posible, pero solo si se abandona la vana pretensión de crear conceptos jurídicos autónomos de Derecho privado, cuando no existe un Derecho privado europeo. La respuesta, ya implícita en normas como el art. 12 del Reglamento «Roma II», es sencilla y funcional: entre partes contratantes, deben utilizarse los foros en materia contractual, con independencia de que la reclamación sea contractual o no. Finalmente, será un foro previsible y operativo ${ }^{44}$. Dicho de otra forma, utilicemos soluciones autónomas de Derecho internacional privado sin recurrir a conceptos jurídicos autónomos de Derecho privado que no tenemos.

43 Baird Textile Holdings Ltd. versus Mark \& Spencer plc. [2001] EWCA Civ 271.

44 El Abogado General DARMON ya había expuesto este planteamiento en sus conclusiones al asunto Kalfelis. Véase, en el mismo sentido, la nota a dicho caso de GaUdeMET-Tallon, H., Rev. crit. DIP, 1989, pp. 120-123. También Font I SegurA, A., «La responsabilidad del porteador efectivo en el Convenio de Bruselas de 1968", Revista de Derecho comunitario europeo, 1999, pp. 187 y 204-206. Y los comentarios al asunto Brogsitter de HAFTEL, B., Rev. crit. DIP, 2014, p. 872; UsUNIER, L., «Torsions et contorsions des situations contractuelles en droit international prive», RTD civ., 2014, p. 848; y SÁNCHEZ LORENZO, S., «Délimitation...», loc. cit., nota 41, p. 472. Recientemente, MüLlER, M., "Objektive Anknüpfungsmomente für Schuldverhältnisse im europäischen IPR und IZVR: Die Behandlung vertraglicher Sahcverhalte», Kohärenz im internationalen Privat-und Verfahrensrecht der Europäischen Union (Jan Von Hein und G. Rühl Hrsg.), Tubinga, Mohr Siebeck, 2016, p. 275. 
29. La naturaleza mítica de las nociones autónomas para el Derecho internacional privado europeo sin un Derecho privado europeo es palpable en otros ámbitos. La STJUE (Sala 1. ${ }^{a}$ ) de 20 de abril de 2016 (asunto C-366/13, Profit Investment SIM SpA/Stefano Ossi y otros) suscita precisamente la cuestión de la calificación de la acción de nulidad o anulación del contrato ${ }^{45}$. Las acciones vinculadas a la nulidad del contrato en el Derecho inglés se reconducen a la restitution y presentan una naturaleza extracontractual o cuasicontractual $^{46}$. De hecho, calificar una acción de restitución por nulidad radical del contrato por un vicio de consentimiento como «contractual» es contradictorio con la jurisprudencia del TJUE que exige, para dicha calificación, la existencia de una obligación libremente asumida por las partes, y pese al fundamento 55 de la sentencia citada resulta difícil concebir cómo puede afirmarse que existe un vínculo entre el contrato y la restitución y una obligación libremente asumida cuando, por ejemplo, un contrato se considera radicalmente nulo o inexistente por falta absoluta de consentimiento o de libertad al prestarlo. La misma paradoja se detecta acerca de la calificación de la responsabilidad frente a terceros de auditores, expertos o empresas clasificadoras ${ }^{47}$.

30. En suma, en este caso los conceptos jurídicos autónomos, contrariando a Denis Lloyd, no solo son pésimos servidores, sino también fantasmales patronos del Derecho internacional privado, al menos hasta que quepa una armonización igualmente avanzada del Derecho privado europeo. Entretanto, como afirma Haimo Schack, la coherencia en el Derecho internacional privado a fuerza de nociones autónomas será más ilusión que realidad ${ }^{48}$.

\section{COHERENCIA NO ES PARALELISMO}

\subsection{Competencia judicial internacional y Derecho aplicable}

31. Como es lógico, el principio de coherencia aplicado a las nociones, conceptos y soluciones utilizados en los distintos textos de Derecho internacional privado suele alcanzarse de forma más natural en el caso de sucesión de reglamentos o textos sobre la misma materia (coherencia vertical) y suscita mayores dudas cuando se trata de textos sobre distintas cuestiones o materias (coherencia horizontal).

32. Los considerandos 7 de los Reglamentos «Roma I» $\mathrm{y}$ «Roma II» formulan el principio de coherencia referido, precisamente, a las relaciones ho-

45 Véase Crawford, E. B. y Carruthers, J. M., loc. cit., nota 6, pp. 13-14.

46 Véase, más en detalle, SÁnchez Lorenzo, S., El Derecho inglés..., op. cit., pp. 139-141.

47 Véase BASEDOW, J., "Coherencia del Derecho internacional privado de la Unión Europea», $A E-$ $D I P r$, t. XVI, 2016, pp. 66-67; «Kohärenz im Internationalen Privat-und Verfahrensrecht der Europäischen Union», Kohärenz im internationalen Privat -und Verfahrensrecht der Europäischen Union (Jan Von Hein und G. Rühl Hrsg.), Tubinga, Mohr Siebeck, 2016, pp. 14-15.

48 ScHACK, H., «Kohärenz im europäischen Internationalen Deliktsrecht», Kohärenz im internationalen Privat -und Verfahrensrecht der Europäischen Union (Jan Von Hein und G. Rühl Hrsg.), Tubinga, Mohr Siebeck, 2016, p. 280. 
rizontales entre los Reglamentos «Bruselas I», «Roma I» $\mathrm{y}$ «Roma II», lo que implica a distintas materias (obligaciones contractuales y no contractuales) y cuestiones (particularmente competencia judicial internacional y ley aplicable). El régimen paralelo de la definición y protección de consumidores pasivos en el art. 6 del Reglamento «Roma I» y en los arts. 17 a 19 del actual Reglamento «Bruselas I bis» se ha invocado como muestra característica del juego de este principio de coherencia horizontal, por más que existan algunas diferencias o aristas en la simetría de ambos textos ${ }^{49}$. El ejemplo, sin embargo, no debe obnubilarnos. El valor esencial en ambos textos es el mismo, y el principio inspirador es idéntico y se inspira en una regla de favor. Ambos textos son coherentes entre sí, en la medida en que se inspiran en el mismo principio de favor. Igual ocurre, por ejemplo, cuando se trata de determinar el lugar de prestación habitual del trabajador, que juega como foro de competencia y como punto de conexión, y cuya interpretación paralela, sobre la base del principio de coherencia, es patente y expresa en la jurisprudencia del TJUE ${ }^{50}$. Otro supuesto de coherencia por "paralelismo axiológico» podría venir dado por la delimitación de la noción de «daño directo» tanto en el Reglamento «Bruselas I bis» como en el Reglamento «Roma II», como acredita la STJUE (Sala 4. ${ }^{\text {a }}$ ) de 10 de diciembre de 2015 (asunto C-350/14, Florin Lazar/Allianz Spa) ${ }^{51}$. En este caso, la idéntica delimitación del concepto se vincula tanto en el foro de competencia como el punto de conexión a las mismas razones de previsibilidad y seguridad jurídica.

33. Sin embargo, el paralelismo se difumina y el principio se pone en cuestión cuando los valores u objetivos a los que responde un foro de competencia y un punto de conexión no son coincidentes, tal y como indicó el TJUE en el asunto Kainz ${ }^{52}$. Frente al paralelismo en la interpretación del concepto

49 Las discordancias entre ambos textos en materia de consumidores existen, pero la incoherencia del respectivo tratamiento de los contratos de seguro resulta más llamativo. Véase, al respecto, KIENINGER, E. M., "Der Schutz schwächerer Personen im Schuldrecht», Kohärenz im internationalen Privat-und Verfahrensrecht der Europäischen Union (Jan Von Hein und G. Rühl Hrsg.), Tubinga, Mohr Siebeck, 2016, pp. 307-335, esp. pp. 322-329.

50 Véanse STJUE (Gran Sala) de 15 de marzo de 2011 (asunto C-29/10, Heiko Koelzsch, ECLI:EU:C:2011:155); STJUE (Sala 4. ${ }^{\text {a }}$ ) de 15 de diciembre de 2011 (asunto C-384/10, Jan Voogsgeerd/Navimer SA, ECLI:EU:C:2011:842); STJUE (Sala 2. ${ }^{\text {a) }}$ de 14 de septiembre de 2017 (asuntos C-168 y 169/2016, Sandra Nogueira y otros/Crewlink Ireland Ltd y Miguel José Moreno Osácar/Ryanair, ECLI:EU:C:2017:688). Sin embargo, el punto de conexión, aun cuando coincide con el foro de competencia y ambos son definidos de idéntica forma, no despliega una función semejante en la consecución del favor laboratoris. En el ámbito de la ley aplicable, la cláusula de excepción contenida en el art. 8 del reglamento «Roma I» puede significar la elusión del punto de conexión a favor de una ley más conectada, sin que semejante excepción atienda a consideraciones materiales [véase VAQUERO LÓPEZ, C., «La determinación del lugar de ejecución de la prestación de vuelo como foro de competencia judicial internacional», La Ley (Unión Europea), diciembre de 2017, núm. 54, pp. 8-9]. El criterio, como foro de competencia, despliega una función muy distinta. En las normas de competencia no existe la necesidad característica del ámbito del Derecho aplicable de elegir una sola ley; el criterio juega, pues, como un foro alternativo más a favor del trabajador demandante. En suma, como señala PAILLER, L., aun cuando existan conceptos de significado paralelo, no conviene confundir los géneros (véase Nota a la sentencia Nogueira, en Journal du droit international, 2018/2, pp. 14-15).

51 ECLI:EU:C:2015:802.

52 «Debe precisarse, acto seguido, que, si bien se deduce ciertamente del considerando 7 del Reglamento núm. 864/2007 que el legislador de la Unión pretendió garantizar la coherencia entre, por una 
de «daño directo», que acabamos de mencionar, resulta curioso comprobar la forma en que dicho paralelismo se esfuma sin aparente motivo cuando de lo que se trata es de determinar la localización del daño en relación con la víctima directa o indirecta. Mientras que, con carácter general, el TJCE había limitado el juego del foro especial en materia de responsabilidad no contractual en relación con los daños provocados a las víctimas directas ${ }^{53}$, en el caso de una acción directa ejercitada por parte de un organismo público que empleaba a la víctima directa y que se subroga en sus derechos (art. 11.2 del Reglamento «Bruselas I»; art. 13.2 del Reglamento «Bruselas I bis»), el TJUE amplía el concepto de víctima del daño a las víctimas que denomina «indirectas» en su reciente decisión en el asunto $K A B E G^{54}$. La aparente incoherencia responde a una diversidad de valores u objetivos de política legislativa en el diseño de los foros. Mientras que el foro general en materia de daños no se inspira en un principio de favor laesi ${ }^{55}$, este principio está muy presente en las reglas en materia de seguros en que se recoge asimismo la competencia judicial internacional en materia de acciones directas. La diversidad axiológica puede ponerse en cuestión, pero explica una desviación, solo aparente, del principio de coherencia en el asunto KABEG.

34. Resulta igualmente paradigmática la variedad de soluciones que, según los casos, se conjugan para localizar a las personas jurídicas, lo que no menoscaba un principio de coherencia bien entendido. La sede social juega en el ámbito del Derecho societario, aunque la administración central o el lugar en que se ubica la agencia imperan en la determinación de la ley aplicable a las obligaciones contractuales y no contractuales. Ambas se combinan con el centro de actividad principal para determinar el foro del domicilio de la sociedad demandada, y se prescinde de ese concepto autónomo si se trata de una competencia exclusiva. En materia de concurso el centro de intereses principales prevalece. La administración central se considera para ubicar el daño, si bien el acontecimiento causa se vincula más al lugar en que despliega su actividad... salvo excepciones ${ }^{56}$.

35. Otro buen ejemplo nos lo sirve el asunto Folien Fischer Fofitec/Ritrama $S p A^{57}$. El Tribunal confirma sin atisbo de dudas, como ya indicamos, la

parte, el Reglamento núm. 44/2001, y, por otra, el ámbito de aplicación material y las disposiciones del Reglamento núm. 864/2007, de ello no se desprende, no obstante, que las disposiciones del Reglamento núm. 44/2001 deban, por tanto, interpretarse a la luz de las del Reglamento núm. 864/2007. En ningún caso la congruencia pretendida puede llevar a interpretar las disposiciones del Reglamento núm. 44/2001 de una manera ajena al sistema y a los objetivos de este» [STJUE (Sala 4. ${ }^{\mathrm{a}}$ ) de 16 de enero de 2014 (asunto C-45/13, Kainz, ECLI:EU:C:2014:7, FJ 20)].

${ }^{53}$ STJCE (Sala 6. ${ }^{\text {a }}$ ) de 11 de enero de 1990 (asunto C-220/1988, Dumez, ECLI:EU:C:1988:8).

${ }^{54}$ STJUE (Sala 3.a) de 1 de julio de 2017 (asunto C-340/16, KABEG, ECLI:EU:C:2017:576).

55 Véase supra nota 32.

${ }^{56}$ Acaso la sede social debería retenerse para las competencias exclusivas, o la administración central para determinar el lugar del acontecimiento causal de un daño [véase el análisis de WEDEMANN, F., "Die Verortung juristischer Personen im Europäischen IPR und IZVR», Kohärenz im internationalen Privat-und Verfahrensrecht der Europäischen Union (Jan Von Hein und G. Rühl Hrsg.), Tubinga, Mohr Siebeck, 2016, pp. 182-201].

57 Véase supra nota 32. 
ausencia de un principio de favor laesi en los foros especiales en materia de obligaciones no contractuales, algo que por otra parte ya venía afirmando el TJUE desde Minas de Potasa. El desdoblamiento entre el foro del acontecimiento causal y el lugar de manifestación del daño no respondían a un valor de protección de la víctima o favor laesi, sino a condicionantes puramente procesales, pues tanto los tribunales de un lugar como de otro están bien situados para la organización del proceso, el primer para determinar la responsabilidad, culpa y causalidad el daño, y el segundo sobre todo para evaluar dicho daño. En el ámbito de la ley aplicable, sin embargo, el valor que sustenta al punto de conexión es diverso y sustantivo, como sugiere el TJUE en el asunto Kainz. De ahí que el art. 4 del Reglamento «Roma II» haya optado por un criterio distinto a la ubicuidad (lex loci damni) que responde mejor a la tendencia hacia modelos sustantivos de responsabilidad objetiva. Salvo en un caso: el de los daños ambientales (art. 7), en que el principio de ubicuidad se retiene aquí por un motivo propio, vinculado no tanto a la protección de la víctima medioambiental como a la consecución de políticas activas de protección del medioambiente. La ubicuidad en competencia judicial internacional y en Derecho aplicable no solo no se justifica de la misma forma, sino que cuando concurren lo hacen por motivos diversos: la coherencia, entendida como "paralelismo», carece entonces de sentido ${ }^{58}$.

36. Por ello, el riesgo de «excesos de coherencia», por retomar la expresión utilizada por Eduardo Álvarez Armas en su comentario ${ }^{59}$ al asunto Kare$d a^{60}$, es evidente. La sentencia Kareda es un caso paradigmático de invocación incorrecta del principio de coherencia. En este asunto, el TJUE calificó como contractual una acción de repetición entre codeudores solidarios de un préstamo. Para reforzar esta calificación, el TJUE invocó expresamente el principio de coherencia y el art. 16 del Reglamento "Roma I» que vendría a establecer la aplicación de la ley rectora del préstamo a la acción de repetición del deudor que ha abonado el crédito contra un codeudor solidario. El primer yerro del TJUE es entender que la obligación de cobertura o corresponsabilidad de los codeudores emana del contrato de préstamo. Este contrato únicamente contempla la obligación solidaria de los codeudores en relación con el prestamista, que puede dirigirse contra cualquiera de ellos por toda la deuda. La obligación solidaria contenida en el contrato de préstamo es simplemente un presupuesto o causa de la obligación de corresponsabilidad entre deudores, que emana de una obligación legal y no convencional, que deriva de la ley aplicable al contrato de préstamo y no del contrato de préstamo, que no es exactamente lo mismo. Al margen de esta circunstancia, la utilización del art. 16

\footnotetext{
58 Véase en particular SCHACK, H., loc. cit., op. cit., passim, nota 48.

59 Álvarez Armas, E., "Continuidad interpretativa (en materia de competencia judicial internacional respecto a acciones de repetición entre codeudores) o exceso de coherencia jurisprudencial por parte del TJUE? (Sentencia del Tribunal de Justicia de 15 de junio de 2017, asunto C-249/16, Kareda $v$. Benkö)», La Ley (Unión Europea), enero de 2018, núm. 55.

60 STJUE (Sala $3 .^{a}$ ) de 15 de junio de 2017 (asunto C-249/16, Saale Kareda/Stefan Benkö, ECLI:EU:C:2017:472).
} 
del Reglamento «Roma I» resulta desafortunada. Estima el TJUE que, dado que el art. 16 del Reglamento «Roma I» somete la relación entre codeudores a la ley rectora del préstamo, la calificación de la acción es contractual. Este argumento, sin embargo, no es del todo convincente: el art. 12 del Reglamento «Roma II» prevé la aplicación de la ley hipotética del contrato a la responsabilidad precontractual, que no por eso deja de ser extracontractual, en particular en el ámbito de la competencia judicial internacional, como acredita el asunto Tacconi ${ }^{61}$. Por el mismo motivo, a pesar de lo dispuesto en el art. 16 del Reglamento «Roma I», la acción entre codeudores solidarios podría ser no contractual a efectos del Reglamento «Bruselas I bis». Pero aunque admitamos una calificación contractual, lo más significativo del caso es que el TJUE, haciendo una aplicación paralela del art. 16 del Reglamento «Roma I», lleva la cuestión competencial al ámbito del contrato entre el acreedor y el deudor, esto es, al contrato de préstamo, que, como contrato de servicios, llama a la aplicación de la letra $b$ ) del art. 7.1 del Reglamento. Sin embargo, la obligación libremente asumida por ambos codeudores, que sirve de base a la demanda, no es una obligación de servicios, sino una obligación de responsabilidad, cobertura o garantía solidaria frente a una deuda, que debe tener su propio lugar de ejecución. Las paradojas que se derivan de haber entendido en este caso la coherencia como paralelismo resultan llamativas. Cabe imaginar a una pareja española que reside en España y es captada por un operador dominicano para adquirir un inmueble en Punta Cana, financiado por una entidad de crédito local. Dado que se trata de un contrato de préstamo al consumo, en caso de impago, en virtud del art. 17 del Reglamento «Bruselas I bis», la entidad financiera deberá reclamar ante los tribunales españoles. En contrapartida, como el servicio financiero se presta en la República Dominicana, la obligación entre los codeudores, ambos consumidores y, por tanto, excluidos de los foros de protección en materia de contratos de consumo ${ }^{62}$, quedaría regida por el Derecho dominicano (art. 16 del Reglamento «Roma I») mientras el art. 7.1.b) del Reglamento «Bruselas I bis» resultaría inoperante al determinar la competencia de los tribunales dominicanos. Lo correcto sería, sin embargo, estimar que la obligación de corresponsabilidad entre los codeudores españoles debía cumplirse en España, lugar de la residencia común de la pareja en el momento de constituirse la obligación solidaria, incluso si uno de ellos hubiese trasladado su domicilio posteriormente a otro Estado miembro, como ocurría en el supuesto del caso Kareda.

37. En consecuencia, el principio de coherencia entre las normas de competencia judicial internacional y las normas de Derecho aplicable no puede implicar un paralelismo automático. Requiere un análisis caso por caso y un plus de motivación que desvele la coincidencia no solo de conceptos o nociones, sino de los valores, principios y motivos de política legislativa en ambos textos, sectores o materias. En ciertos casos, igual que ocurre con el

\footnotetext{
${ }^{61}$ STJCE de 17 de septiembre de 2002 (asunto C-334/2000, Tacconi, ECLI:EU:C:2002:499).

${ }^{62}$ STJUE de 5 de diciembre de 2013 (asunto C-508/12, Vapenik, ECLI:EU:C:2013:790).
} 
alcance del principio de ubicuidad en materia de daños ${ }^{63}$, las discordancias o aparentes incoherencias están plenamente justificadas en variaciones en tales valores, principios o motivos. Así, el lugar de ejecución del contrato no puede interpretarse de la misma forma en el art. 7.1 del Reglamento "Bruselas I bis» y en el art. 9 del Reglamento «Roma I»: el sentido que tiene la aplicación correctiva de las leyes de policía del país de ejecución del contrato justifica una interpretación restrictiva que no tiene por qué coincidir necesariamente con la del foro de competencia, que busca facilitar el acceso a la justicia ${ }^{64}$. La regla del «mosaico» que se desprende de forma natural del art. 4 del Reglamento «Roma II» podría ser aplicada a la diversidad de leyes derivadas de una violación de un derecho de la personalidad, aunque esta cuestión esté actualmente excluida de su ámbito de aplicación; sin embargo, razones vinculadas al derecho a la tutela judicial efectiva podrían justificar llevar más lejos incluso de lo que propone la sentencia eDate Advertising ${ }^{65}$ la ruptura de la regla a favor de la acumulación de las reclamaciones ante un solo tribunal. También resulta razonable que nociones comunes, como residencia habitual, domicilio o establecimiento, se interpreten de forma diferente según se trate de foros de competencia o de puntos de conexión. Aunque en ambos ámbitos se predica el principio de proximidad, mientras que los foros de competencia orientan dicho principio teniendo en cuenta la tutela judicial efectiva y los derechos de defensa, los puntos de conexión aquilatan más el concepto por razones de eficiencia económica y siempre sobre la base del carácter excluyente de la ley aplicable, frente a la posibilidad concurrente de foros de protección. La propia materia puede justificar modulaciones. El principio de favor en materia alimenticia o de responsabilidad parental puede justificar un concepto más amplio de residencia habitual que en materia sucesoria o de obligaciones ${ }^{66}$.

38. En contrapartida, algunas veces las discrepancias o ausencias de paralelismo sí pueden reflejar incoherencias lógicas o axiológicas. En el ámbito de la responsabilidad por productos impera la denominada «cláusula de comercialización», que permite al productor evitar la aplicación de la ley de la residencia habitual de la víctima, del lugar de adquisición del producto o del lugar en que se produjo el daño, si el producto no se comercializó en dicho país (art. 5 del Reglamento «Roma II»). La regla se fundamenta aparentemente en la previsibilidad, pero su razón de ser más profunda es una regla clásica de análisis económico del Derecho, de reparto de costes y riesgos. El productor no debe asumir un riesgo que no le produjo ningún beneficio y que es imputable a la conducta del consumidor. En esencia, el productor pasivo

63 Véase ScHAK, H., loc. cit., op. cit., nota 48, pp. 279-303.

${ }^{64}$ No parecen compartir esta idea CraWford, E. B. y CARruthers, J. M., loc. cit., nota 6, p. 8.

65 STJUE (Gran Sala) de 25 de octubre de 2011 (asuntos C-509/09 y C-161/10, e-Date Advertising/X y Oliver Martínez y Robert Martínez/MGN Limited, ECLI:EU:C:2011:685).

66 Sobre las posibles diferentes interpretaciones de la «residencia habitual» en los textos europeos, véase LURGER, B., «Die Verortung natürlichen Personen im europäischen IPR und IZVR (Wohnsitz, gewöhnlicher Aufenthalt, Staatsangehörigkeit», Kohärenz im internationalen Privat -und Verfahrensrecht der Europäischen Union (Jan Von Hein und G. Rühl Hrsg.), Tubinga, Mohr Siebeck, 2016, pp. 202-236. 
tiene una protección equivalente al consumidor pasivo, y el consumidor activo su justo castigo en ambos casos. Pero este valor es perfectamente trasladable al ámbito de la competencia judicial internacional, de forma que debería excluirse el foro del lugar de manifestación del daño en supuestos similares ${ }^{67}$. De hecho, el TJUE llega por otra vía a esta conclusión en el asunto Kolassa ${ }^{68}$, donde la previsibilidad de comercialización en realidad aparece implícita en la solución del caso respecto de un producto financiero ${ }^{69}$. En el ámbito de la competencia judicial internacional la aplicación del análisis económico del Derecho conduce en este caso a limitar el foro de competencia por implicar una carga procesal irrazonable para el demandado. La razonabilidad, en estos casos, se mide en términos económicos de costes, beneficios y riesgos.

39. Otro buen ejemplo de incoherencia por falta de paralelismo puede hallarse en la exclusión de los foros de protección respecto de las partes no débiles que se subrogan en los derechos de la parte débil. En el caso de los organismos públicos que se subrogan en los derechos del acreedor alimenticio, tanto la jurisprudencia del TJUE ${ }^{70}$ como el propio Reglamento «Bruselas III» (art. 2.10) han excluido la extensión del foro a partes no débiles. Aunque el TJUE había mantenido un criterio muy similar en los supuestos de acción directa contra el asegurador en caso de subrogación de un organismo público en los derechos de la víctima ${ }^{71}$, en el asunto $K A B E G$ modifica su doctrina y aplica un criterio particular que va a poner en cuestión el principio de coherencia. Por una parte, señala que la noción de «parte más débil» tiene una acepción más amplia en materia de seguros que en materia de contratos celebrados por consumidores o de contratos de trabajo (o en materia de alimentos, cabría añadir). Por otra, como ya señalamos más arriba, va a mantener un concepto amplio de "víctima indirecta», permitiendo al empleador público que se subroga en los derechos de la víctima la utilización del foro de su propio domicilio. En el asunto ÖFAB ${ }^{72}$, el TJUE había mantenido que una cesión de créditos operada por el acreedor inicial pueda tener incidencia en la determinación del tribunal competente en razón del foro especial en materia de daños sería contrario a uno de los objetivos del Reglamento "Bruselas I», a saber, la previsibilidad de los foros contemplada en su considerando 11. A la luz del asunto $K A B E G$, cabe preguntarse legítimamente si los principios de proximidad y previsibilidad no sufren las consecuencias de una interpretación extensiva de la noción de "víctima» en relación con las acciones direc-

67 Así lo hemos defendido en Fernández Rozas, J. C. y SÁnchez Lorenzo, S., Derecho internacional privado, 9. . ed., Cizur Menor, Rhomson-Reuters, 2016, p. 644.

68 STJUE (Sala 4..$^{\text {) }}$ de 28 de enero de 2015 (asunto C-375/13, Kolassa, ECLI:EU:C:2015:37).

69 Véase, con más detalle, SÁnchez LoREnzo, S., "Prévisibilité du lieu où le dommage survient: vers une règle spéciale en matière de "produits", même financiers", Journal de droit international, 2016/4, pp. 1461-1464.

70 STJUE (Sala 5. ${ }^{\text {a) }}$ de 15 de enero de 2004 (asunto C-33/2001, Freistaat Bayern/Jan Blijdenstein, ECLI:EU:C:2004:21).

${ }_{71}$ STJUE (Sala 3. ${ }^{\text {a }}$ ) de 13 de diciembre de 2009 (asunto C-347/08, Vorarlberger Gebietskrankenkasse, ECLI:EU:C:2009:561).

72 STJUE (Sala 5. ${ }^{\text {a) }}$ de 18 de julio de 2013 (asunto C-147/12, ÖFAB, ECLI:EU:C:2013:490). 
tas contra los aseguradores, que podrían implicar a varias víctimas directas e indirectas así como a distintas acciones directas bastante imprevisibles y consistentes en opciones diversas entre los foros alternativos, sobre todo si el domicilio de la víctima directa difiere del domicilio de la víctima indirecta. En contrapartida, el TJUE estima en el asunto $K A B E G$ que el alto grado de previsibilidad estaría en entredicho si hubiera que apreciar caso por caso la debilidad de la víctima.

40. Finalmente, cabe hacer una mención a la coherencia de ciertos principios de Derecho internacional privado general, que parecen obedecer a reforzar el principio de coherencia entre la dimensión judicial y la dimensión sustantiva del Derecho internacional privado. Acaso el más socorrido sea la recurrente aparición fantasmal del principio lex fori in foro proprio, particularmente en materias de estatuto personal ${ }^{73}$. No es un principio, sin embargo, que se sustente más allá de la específica coyuntura de cada texto. Este efecto no se consigue, por ejemplo, con el juego de las normas de competencia judicial del Reglamento «Bruselas II bis» y de las normas de conflicto del Reglamento «Roma III» en materia de divorcio. Tampoco en ámbitos de protección como los contratos de seguro, al menos en materia de acciones directas: la jurisprudencia Odenbreit ${ }^{74}$ abrió una vía para sortear este principio de forma que el domicilio de la víctima sirviera a la competencia judicial internacional al tiempo que la ley aplicable se determina con normalidad a través del forum delicti commissi. Pero incluso cuando el principio es evidente, como en materia de medidas de protección de menores (art. 15 del Convenio de La Haya de 1996), la complejidad transversal obliga a algunas piruetas interpretativas, pues la norma de ley aplicable no se refiere a la aplicación de la lex fori, sino de la ley del tribunal que conoce en virtud de las disposiciones del Capítulo III del Convenio, que no son exactamente iguales que las contenidas en materia de competencia judicial internacional en el Reglamento «Bruselas II bis».

\subsection{Derecho conflictual y Derecho material}

41. Los argumentos expuestos no se circunscriben a las relaciones horizontales entre textos europeos relativos a la competencia judicial internacional y al Derecho aplicable. Idéntico análisis cabe realizar respecto al juego del principio de coherencia entre reglamentos europeos que contengan soluciones conflictuales o materiales a la cuestión del Derecho aplicable en materias diversas, así como a las relaciones entre las normas de competencia judicial internacional y las reglas de Derecho privado material.

\footnotetext{
73 Véase al respecto GrUBER, U. P., «Der Schutz schwächerer Personen im Familien-und Erbrecht», Kohärenz, im internationalen Privat -und Verfahrensrecht der Europäischen Union (Jan Von Hein und G. Rühl Hrsg.), Tubinga, Mohr Siebeck, 2016, pp. 350-354.

${ }^{74}$ STJCE (Sala 2. ${ }^{\mathrm{a}}$ ) de 13 de diciembre de 2007 (asunto C-463/06, FBTO Schadeverzekeringen NV/ Jack Odenbreit, ECLI:EU:C:2007:792). Véase BASEDOW, J., «Coherencia...», loc. cit., nota 47, pp. 69-70; «Kohärenz...», loc. cit., op. cit., nota 47, pp. 17-18.
} 
42. Destaca, en particular, la diversidad de fórmulas con que se aborda la cuestión de la autonomía conflictual. No extraña que la posibilidad de elegir la ley aplicable se restrinja en materias como las causas matrimoniales o las sucesiones, pero es más sorprendente que en materia de obligaciones, por ejemplo, las condiciones para inferir una elección tácita sean diferentes en los Reglamentos «Roma I» y «Roma II», según las versiones lingüísticas. Mientras que en español o francés en ambos textos se requiere que dicha elección sea «inequívoca» o "certaine», en otras versiones (inglés o alemán) la elección tácita debe ser «clara» en «Roma I» y «con certeza razonable» en «Roma II», sin que se atisbe a adivinar la razón de la diversa locución ${ }^{75}$. Por otra parte, como hemos dicho, es lógico que el alcance de la elección sea distinto en materia patrimonial y en el Derecho de familia sucesiones, y también que la validez de la elección se someta en los ámbitos disponibles a soluciones conflictuales, mientras que en el sector más comprometido con el interés público o la protección de los sujetos del Derecho de familia o sucesiones las condiciones de validez formal sean sustanciales. Pero otras diferencias se antojan menos razonables. Cabe reseñar, por ejemplo, que mientras el momento de elección de la ley aplicable a las obligaciones contractuales es flexible (art. 3 del Reglamento «Roma I»), la elección de la ley aplicable al divorcio tras la interposición de la demanda no está permitida (art. 5 del Reglamento «Roma III») ${ }^{76}$.

43. Al margen de esta cuestión, las soluciones conflictuales no siempre abocan a una coherencia perfecta. La compleja cuestión de la responsabilidad precontractual es un buen ejemplo. El art. 1 del Reglamento «Roma I» excluye de su ámbito de aplicación, sin distinción, las obligaciones que se derivan de los tratos previos a la celebración de un contrato, y el considerando 10 lo justifica por haberse regulado en el art. 12 del Reglamento «Roma II». Pero, en realidad, el art. 12 del Reglamento «Roma II» sí distingue, y solo contempla y resuelve la responsabilidad precontractual en la medida en que la obligación precontractual sea «extracontractual», lo que deja abierto en todo caso el problema calificatorio ${ }^{77}$.

44. Las incoherencias aumentan a la hora de conjugar soluciones procesales, materiales y conflictuales ${ }^{78}$. Así, la validez de las cláusulas de elección de fuero encuentran una solución conflictual en el Reglamento «Bruselas I

75 Véase Basedow, J., «Coherencia...», loc. cit., nota 47, p. 63; «Kohärenz...», loc. cit., op. cit., nota 47 , pp. 11-12.

76 Véase Basedow, J., "Coherencia...», loc. cit., nota 47, p. 64; «Kohärenz...», loc. cit., op. cit., nota 47, p. 12; KoHLER, Ch., «L'autonomie de la volonté en droit international privé. Un principe universel entre libéralisme et étatisme», $R$. des $C$., t. 359, 2013, pp. 28 y ss.

77 Véase una visión diferente y más amable con la coherencia formal, aunque con consecuencias poco funcionales, en ARENAS GARcía, A., «La regulación de la responsabilidad precontractual en el Reglamento "Roma II" ", Anuario español de Derecho internacional privado, vol. VII, 2007, pp. 322-336; CraWford, E. B. y CARruthers, J. M., loc. cit., nota 6, p. 9.

78 Véase Maultzsch, F., «Parteiautonomie im Internationalem Privat- und Zivilverfahrensrecht», Kohärenz, im internationalen Privat -und Verfahrensrecht der Europäischen Union (Jan Von Hein und G. Rühl Hrsg.), Tubinga, Mohr Siebeck, 2016, pp. 153-181. 
bis»: mientras que la validez formal se resuelve en el propio art. 25, la validez sustancial se somete a lo previsto en la legislación del tribunal elegido, que podrá someter la cuestión a la ley del foro o a la propia lex contractus. La nulidad de pleno Derecho de la cláusula de elección de fuero conforme a la lex fori puede, sin embargo, fundarse en motivos sustanciales (vicios de consentimiento) muy cercanos a las exigencias de forma. Es el caso de las cláusulas contenidas en condiciones generales dentro de contratos de adhesión, incluso al margen de que formalmente se cumplan las condiciones formales referidas en el art. 25, tal y como las interpreta el $\operatorname{TJUE}^{79} \mathrm{o}$, en el ámbito de los contratos de consumidores, a pesar de respetar lo contemplado en el art. 18 del Reglamento «Bruselas I bis». Se da la circunstancia de que la validez sustancial de estas cláusulas está mediatizada por las propias directivas europeas en materia de protección del consumidor, que actúan como una lex fori u orden público del foro cualificados.

45. El mismo análisis cabe en el ámbito de las cláusulas de elección de ley aplicable, permitidas a priori por el art. 3 o por el art. 6 del Reglamento «Roma I», pero nulas de conformidad con los Derechos nacionales que en muchos casos transponen directivas europeas ${ }^{80}$. Así, la STJUE (Sala 3. ${ }^{a}$ ) de 28 de julio de 2016 (asunto C-191/15, Verein für Konsumenteninformation/ Amazon EU Sàrl) ${ }^{81}$ ha ido más allá de esta protección conflictual, pues establece que, de conformidad con la Directiva 93/13, una cláusula de elección de la ley aplicable introducida en condiciones generales que designe la aplicación de la ley del establecimiento del proveedor o co-contratante del consumidor se considerará abusiva y, en consecuencia, nula si induce a error o engaño al consumidor, al no hacer una referencia expresa a la mayor protección que le cabe al consumidor conforme a las normas imperativas de la ley de su residencia habitual en virtud del art. 6.2 del Reglamento «Roma I» ${ }^{82}$.

79 STJCE de 14 de diciembre de 1976 (asunto 24/1976, Salotti); STJUE (Sala 1. a) de 20 de abril de 2016 (asunto C-366/13, Profit Investment SIM SpA/Stefano Ossi y otros, ECLI:EU:C:2016:282); STJUE (Sala 2. ${ }^{\text {a) }}$ de 7 de julio de 2016 (asunto C-222/15, Höszig Kft./Alstom Power Thermal Services, ECLI:EU:C:2016:525); STJUE (Sala 7. ${ }^{\text {) }}$ ) de 8 de marzo de 2018 (asunto C-64/17, Saey Home \& Garden NV/SA c. Lusavouga-Máquinas e Acessórios Industriais SA, ECLI:EU:C:2018:173). El Auto del Juzgado de Primera Instancia núm. 3 de Moncada, de 10 de mayo de 2017, mantiene una restricción para la validez de las cláusulas de sumisión a favor de los tribunales de terceros Estados contenidas en contratos de adhesión, incluso entre profesionales, sobre la base de la protección del adherente en la legislación sobre condiciones generales de contratación.

${ }^{80}$ Debe tenerse en cuenta que, más allá del propio art. 6.2, una cláusula de elección de ley aplicable en un contrato celebrado por consumidor activo o pasivo, protegido o no, puede ser considerada abusiva y nula en razón del propio Derecho europeo y de la transposición de la Directiva 93/13/CEE en los sistemas nacionales. Así lo han pronunciado, por ejemplo, la Sentencia del Juzgado de lo Mercantil núm. 5 de Madrid, núm. 113/2013, de 30 de septiembre, o la Sentencia del Juzgado de lo Mercantil núm. 1 de Valencia, núm. 37/2017, de 16 de febrero, en relación con la sumisión al Derecho irlandés de un contrato de adhesión de transporte aéreo de pasajeros suscrito por un consumidor residente en España.

81 ECLI:EU:C:2016:612.

82 La complejidad de las relaciones entre Derecho internacional privado conflictual y Derecho material se acentúan en virtud de los déficits de armonización del segundo. El art. 3.4 del Reglamento «Roma I» es paradigmático en este sentido. Se diseñó por analogía con los contratos puramente internos (art. 3.3), sobre la base dos presupuestos falsos: la existencia de un Derecho contractual europeo y la identidad de razón con los supuestos internos. La regla resulta innecesaria e incompleta. Por una 
46. El riesgo de que el paralelismo sea incompatible con la coherencia es mucho mayor cuando la coherencia se plantea entre normas de Derecho internacional privado y normas de Derecho material. La razón parece obvia: mientras que las normas de conflicto o de competencia judicial internacional comparten ciertos objetivos comunes, como la proximidad o la previsibilidad, las normas de Derecho material suelen atender a objetivos diversos, que a su vez se distancian más en el caso de normas materiales de Derecho público. Los asuntos Nogueira ${ }^{83}$ proporcionan un ejemplo explícito de la lejanía de los valores de las normas de competencia judicial internacional en relación con las normas de Derecho material, que es puesta de manifiesto por el propio TJUE. En los dos asuntos acumulados se trataba de interpretar el foro de competencia del art. 19.2 del Reglamento "Bruselas I» en relación a contratos de trabajo de determinado personal de transporte aéreo. En lo que aquí interesa, la cuestión estribaba en determinar si para precisar el lugar de prestación habitual del trabajo cabía utilizar la noción de "base de afectación» ${ }^{84}$ contemplada en el Anexo III del Reglamento (CEE) núm. 3922/91, del Consejo, de 16 de diciembre, relativo a la armonización de normas técnicas y procedimientos administrativos aplicables a la aviación civil, noción que sirve asimismo para determinar la legislación de seguridad social aplicable a los miembros de las tripulaciones de vuelo y cabina de conformidad con lo dispuesto en el Reglamento (CE) núm. 883/2004, del Parlamento Europeo y del Consejo, de 29 de abril, sobre la coordinación de los sistemas de seguridad social. Al negar la extrapolación automática de la noción de «base de afectación» al foro de competencia, el TJUE subrayó la falta de paralelismo axiológico. Mientras que el Reglamento «Bruselas I» tiene como objetivos facilitar el acceso a la justicia, la previsibilidad de los foros de competencia judicial internacional y la protección de los trabajadores (FJ 47), el Reglamento (CEE) núm. 3.922 persigue la armonización de normas técnicas y procedimientos administrativos aplicables a la aviación civil (FJ 66) y el Reglamento núm. 833/2004, «además de la libre circulación de las personas, contribuir a mejorar el nivel de vida y las condiciones de empleo de estas» (FJ 74), de forma que «el concepto de "lugar en el cual, o a partir del cual, el trabajador desempeñare habitualmente su trabajo" no puede asimilarse a ningún otro concepto que figure en otro acto de Derecho de la Unión» (FJ 65).

\footnotetext{
parte, el Derecho derivado introduce normas imperativas cuyo ámbito de aplicación se extiende incluso si solo una circunstancia se encuentra vinculada a territorio europeo (situación del inmueble en los contratos de aprovechamiento por turno de bienes inmuebles, lugar de distribución para los contratos de agencia, etc.), y además con independencia de que el contrato se rija por la ley de un tercer Estado en virtud de la elección de las partes (art. 3 del Reglamento) o en defecto de elección (art. 4), como confirman la STJCE de 9 de noviembre de 2000 (asunto C-381/98, Ingmar, ECLI:EU:C:2000:605) y la STJUE (Sala 1. ${ }^{\mathrm{a}}$ ) de 16 de febrero de 2017 (asunto C-507/15, Agro Foreign Trade \& Agency Ltd c. Petersime NV, ECLI:EU:C:2017:129). Véase in extenso sobre esta cuestión, SÁNCHEZ LoRENZo, S., "Choice of Law...», loc. cit., nota 20, pp. 77-79.

83 Véase supra, nota 50.

84 «Lugar asignado por el operador a cada tripulante, en el cual habitualmente este comienza y termina uno o varios periodos de actividad y en el que, en condiciones normales, el operador no se responsabiliza del alojamiento del tripulante».
} 


\section{CONCLUSIÓN: EL JUEGO DE LOS VALORES REDUCE LA UNIDAD DE LOS CONCEPTOS}

47. La afirmación del TJUE en el asunto Nogueira debe servirnos de colofón: el principio de coherencia no es una herramienta interpretativa a priori. El paralelismo de nociones, conceptos y soluciones no puede ser automático. La diversidad axiológica, el juego de los valores, limita y reduce la unidad de los conceptos. Los ejemplos analizados a lo largo del trabajo nos permiten confirmar la hipótesis formulada en la introducción. Para ser coherentes con el principio de coherencia, este únicamente puede ser entendido de forma dialéctica, relativa y dionisíaca. Requiere un análisis caso por caso de la correspondencia de valores y objetivos perseguidos por las distintas normas jurídicas de Derecho europeo en que se inserta un concepto, una noción o una determinada solución. El principio de coherencia no puede ser entendido en clave funcional o práctica, como una herramienta de consistencia puramente formal para allanar el camino a la interpretación del Derecho internacional privado europeo. En otros términos, el principio de coherencia no puede ser asimilado a un paralelismo meramente formal de conceptos, nociones o soluciones, sino que opera únicamente a partir del postulado de un paralelismo axiológico de tales conceptos, nociones y soluciones. La jurisprudencia de valores se impone a la de los conceptos o, remedando nuevamente a Denis Lloyd, los conceptos europeos se erigen como buenos servidores, y no como malos patronos azuzados por la burda lógica de la integración.

\section{RESUMEN \\ EL PRINCIPIO DE COHERENCIA EN EL DERECHO INTERNACIONAL PRIVADO EUROPEO}

El presente estudio contiene un análisis crítico del alcance del principio de coherencia en el ámbito del Derecho internacional privado europeo. Se analizan en primer términos los planos en que se manifiesta la exigencia de coherencia jurídica entre conceptos, nociones y soluciones jurídicas: vertical (textos normativos sucesivos sobre la misma materia), horizontal (textos normativos sobre distintas materias) y transversal (textos normativos europeos y no europeos). La lógica de la integración puede conducir a una comprensión formal del principio de coherencia entendida como mero paralelismo entre conceptos y soluciones jurídicas en la interpretación sistemática del Derecho internacional privado europeo. A partir de un análisis casuístico, se pone de manifestó no solo la realidad de este riesgo, sino la necesidad de una comprensión axiológica, relativa y dialéctica del principio de coherencia, que requiere una comparación de objetivos y valores jurídicos en cada caso concreto, así como descartar cualquier posibilidad recurrir a un paralelismo automático de conceptos o soluciones jurídicas.

Palabras clave: conceptos jurídicos autónomos en la EU, Derecho internacional privado europeo, interpretación sistemática, principio de coherencia. 


\begin{abstract}
THE CONSISTENCY PRINCIPLE IN EUROPEAN PRIVATE INTERNATIONAL LAW

The present study contains a critical analysis of the scope of the principle of coherence or consistency principle in the field of European private international law. First, the author analyzes the areas in which the requirement of legal coherence between concepts, notions and legal solutions is required: vertical (successive normative texts on the same subject), horizontal (normative texts on different subjects) and transversal (European and non European legal rules). The logic of integration can lead to a formal understanding of the principle of coherence as a mere parallelism between concepts and legal solutions in the systematic interpretation of European private international law. A casuistic analysis tries to demonstrate such a risk as well as the need for an axiological, relative and dialectical understanding of the coherence principle, which requires a comparison of legal objectives and values issue-by-issue, discarding any possibility to resort to an automatic parallelism of concepts or legal solutions.
\end{abstract}

Keywords: autonomous EU legal concepts, consistency principle, european private international law, systematic interpretation. 